\title{
Clinical Use of Cerebral Microdialysis in Patients with Aneurysmal Subarachnoid Hemorrhage-State of the Art
}

\section{Raimund Helbok ${ }^{* t}$, Mario Kofler ${ }^{\dagger}$, Alois Josef Schiefecker, Maxime Gaasch, Verena Rass, Bettina Pfausler, Ronny Beer and Erich Schmutzhard}

OPEN ACCESS

Edited by:

Adel Helmy,

University of Cambridge,

United Kingdom

Reviewed by:

Diederik Bulters,

University Hospital Southampton

NHS Foundation Trust,

United Kingdom

Martin Hunn,

The Alfred Hospital, Australia

*Correspondence:

Raimund Helbok

raimund.helbok@i-med.ac.at

tThese authors have contributed equally to this work.

Specialty section:

This article was submitted to

Neurotrauma,

a section of the journal

Frontiers in Neurology

Received: 20 May 2017 Accepted: 09 October 2017 Published: 03 November 2017

Citation:

Helbok R, Kofler M, Schiefecker AJ,

Gaasch M, Rass V, Pfausler B,

Beer $R$ and Schmutzhard E (2017)

Clinical Use of Cerebral

Microdialysis in Patients with

Aneurysmal Subarachnoid Hemorrhage-State of the Art.

Front. Neurol. 8:565.

doi: 10.3389/fneur.2017.00565
Neurological Intensive Care Unit, Department of Neurology, Medical University of Innsbruck, Innsbruck, Austria

Objective: To review the published literature on the clinical application of cerebral microdialysis (CMD) in aneurysmal subarachnoid hemorrhage $(\mathrm{SAH})$ patients and to summarize the evidence relating cerebral metabolism to pathophysiology, secondary brain injury, and outcome.

Methods: Study selection: Two reviewers identified all manuscripts reporting on the clinical use of CMD in aneurysmal SAH patients from MEDLINE. All identified studies were grouped according to their focus on brain metabolic changes during the early and subacute phase after $\mathrm{SAH}$, their association with mechanisms of secondary brain injury and outcome.

Results: The review demonstrated: (1) limited literature is available in the very early phase before the aneurysm is secured. (2) Brain metabolic changes related to early and delayed secondary injury mechanisms may be used in addition to other neuromonitoring parameters in the critical care management of SAH patients. (3) CMD markers of ischemia may detect delayed cerebral ischemia early (up to $16 \mathrm{~h}$ before onset), underlining the importance of trend analysis. (4) Various CMD-derived parameters may be associated with patient outcome at 3-12 months, including CMD-lactate-to-pyruvate-ratio, CMD-glucose, and CMD-glutamate.

Conclusion: The clinical use of CMD is an emerging area in the literature of aneurysmal SAH patients. Larger prospective multi-center studies on interventions based on CMD findings are needed.

Keywords: subarachnoid hemorrhage, neuromonitoring, cerebral microdialysis, brain metabolism, treatment

\section{INTRODUCTION}

First reports on monitoring of brain metabolism using cerebral microdialysis (CMD) in patients with subarachnoid hemorrhage (SAH) date back to the year 1992 (1). Despite the long-standing availability of this technique, recommendations for treatment decisions based on CMD monitoring have just been recently published as a consensus statement by clinical experts (2).

Cerebral microdialysis has improved our understanding of pathophysiological mechanisms of early and delayed brain injury in SAH patients by providing metabolic information derived from brain tissue on a cellular level, in addition to intracranial pressure (ICP), cerebral perfusion pressure (CPP), cerebral blood flow $(\mathrm{CBF})$, brain tissue oxygen tension $\left(\mathrm{P}_{\mathrm{bt}} \mathrm{O}_{2}\right)$, and electrographic 
monitoring (electroencephalography and electrocorticography). So far, changes in brain metabolism have been associated with known complications after SAH and may also help to detect impending secondary brain injury early or before they have evolved into irreversibility. Moreover, abnormalities in CMD-derived parameters have been linked to poor brain tissue and functional outcome and may therefore be integrated in the multimodal approach of neuroprognostication. In addition, the effect of commonly applied pharmacological and non-pharmacological treatments on brain metabolism can be studied on an individual level, thereby enhancing the concept of personalized medicine in neurocritical care patients.

\section{Microdialysis Methodology}

The principle of CMD is to mimic a capillary blood vessel in the brain for the assessment of local cerebral metabolism (3). A tubular semi-permeable membrane on the tip of the CMD catheter is perfused with an isotonic or colloid-enriched fluid that equilibrates with the extracellular space by simple diffusion. All molecules small enough to pass the membrane follow their electro-chemical gradient into the tube. Established catheters have a membrane length of $1 \mathrm{~cm}$ and pore sizes of either 20 or $100 \mathrm{kDa}$, which do not show differences in the recovery of small molecules (4). A perfusion speed of $0.3 \mu \mathrm{l} / \mathrm{min}$ is recommended in clinical use, which leads to a relative recovery rate (dialyzate concentration divided by true concentration) of about $70 \%$ for the most commonly assessed molecules (5).

Criteria for CMD monitoring are not well defined. It can be used as part of the "multimodal neuromonitoring bundle" (Figure 1A) in ventilated ("poor-grade") patients or in patients with a secondary neurological deterioration. As a primary monitoring device, the probe should be placed in the frontal lobe (anterior/middle cerebral artery watershed), ipsilateral to the ruptured aneurysm, or the maximal blood clot load. When used in patients with secondary deterioration, location can also be guided by local practice to identify tissue at risk (for example, by CT perfusion or transcranial ultrasound) $(2,6)$. The catheter can be inserted into the brain tissue either by using a cranial access device (bolt) or by tunneling (Figure 1A), penetrating the skull via a craniotomy (Figure 1B) or a twist drill hole. The dialyzate of the first hours should be discarded due to the insertion trauma and dilution effect of the flush sequence filling the system.

\section{Interpretation of Data}

Concentrations of CMD parameters represent the local metabolic environment surrounding the membrane and cannot be extrapolated to other regions of the brain. Knowledge of catheter location is therefore mandatory for data interpretation. The gold tip of the CMD probe is visible on head CT (Figure 2B), thus its exact location in the brain can be determined and classified by the monitored tissue (gray vs. white matter), lobe, or by the spatial relation to focal pathologies (intralesional/perilesional vs. radiologically normal-appearing brain tissue). The dependency of molecular concentrations on probe location argues for the interpretation of temporal dynamics (trend analysis) in addition to absolute values. Calculating ratios of different CMD parameters (e.g., CMD-lactate-to-CMD-pyruvate-ratio, CMD-LPR) creates variables independent of absolute concentrations and recovery.

The dialyzate is sampled into microvials and analyzed for point of care parameters including CMD-glucose, CMD-lactate, CMD-pyruvate, CMD-glutamate, and CMD-glycerol at the patient's bedside. A measurement interval of $1 \mathrm{~h}$ is commonly used in clinical practice.

Glucose is an important energy substrate for neuronal tissue. Its concentration in the brain depends on systemic supply, diffusivity in the brain tissue, and local consumption. In the process of aerobic glycolysis, it is metabolized to pyruvate and further converted into acetyl-coenzyme A, which is used for mitochondrial energy production. Under conditions of brain tissue hypoxia or mitochondrial dysfunction, pyruvate is fermented into lactate. The LPR reflects the cytoplasmatic redox state and is a marker of anaerobic metabolism and/or mitochondrial dysfunction. The concept of mitochondrial dysfunction arose from observations of impaired cerebral energy metabolism despite normal perfusion and substrate availability. The underlying pathophysiological mechanisms are not sufficiently elucidated. CMD-glutamate has fewer clinical implications, however, elevated concentrations of this excitatory neurotransmitter are considered to be a marker of ischemia and excitotoxicity. Glycerol is a component of neuronal cell membranes, thus CMD-glycerol concentrations are a surrogate marker of cell membrane damage, e.g., under conditions of hypoxia or ischemia.

\section{MATERIALS AND METHODS}

The aim of this review is to summarize the current knowledge of this technique in the critical care management of SAH patients and to discuss its limitations. A MEDLINE search was performed to identify all studies reporting on the clinical use of CMD in aneurysmal SAH patients. The selection process is summarized in Figure 2. All identified studies were grouped according to their focus on the brain metabolic changes during the early and subacute phase after SAH, their association with mechanisms of secondary brain injury and outcome.

\section{Definitions}

The early phase was defined as the first $72 \mathrm{~h}$ after SAH, commonly referred to as "early brain injury" (EBI) (7). Pathological threshold values of parameters commonly given in the SAH literature are CMD-glucose $<0.7 \mathrm{mmol} / \mathrm{l}$ (referred to as neuroglucopenia), CMD-lactate $>4 \mathrm{mmol} / \mathrm{l}$, CMD-pyruvate $<120 \mu \mathrm{mol} / \mathrm{l}$, CMDglutamate $>10 \mu \mathrm{mol} / \mathrm{l}, \mathrm{CMD}$-glycerol $>50 \mu \mathrm{mol} / \mathrm{l}$, and CMDLPR $>40$. A CMD-LPR $>40$ is referred to as metabolic distress. Recently, the pattern of mitochondrial dysfunction was defined as CMD-LPR > 30 together with CMD-pyruvate levels $>70 \mu \mathrm{mol} / \mathrm{l}$. Important metabolic profiles in SAH patients are shown in Table 1.

\section{RESULTS}

\section{The Clinical Use of CMD in the Acute Phase after SAH}

The initial phase after SAH is commonly referred to as "early brain injury" and comprises the first $72 \mathrm{~h}$ after the bleeding (7), which 
A

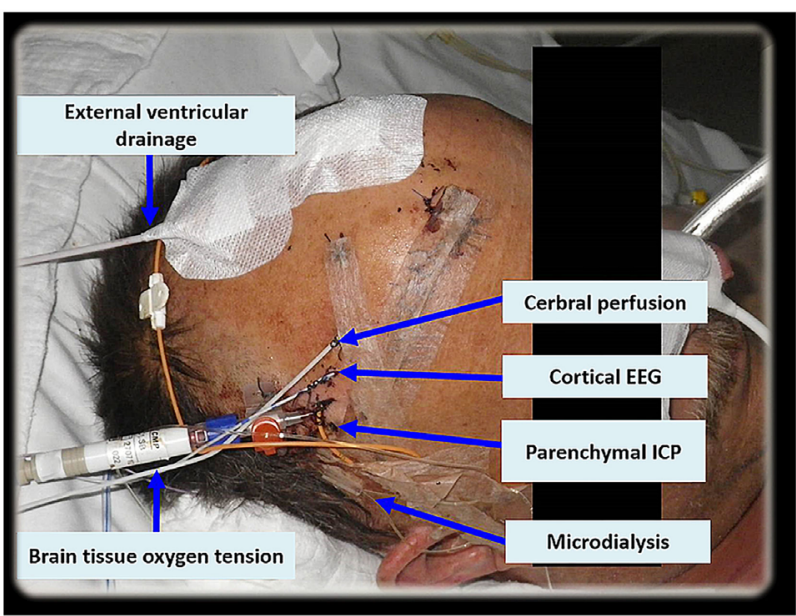

B

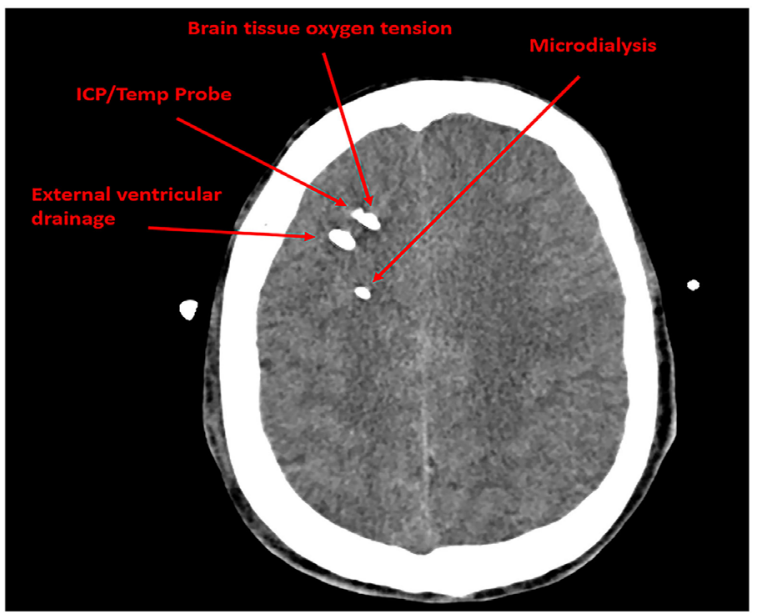

FIGURE 1 | In (A), multimodal neuromonitoring catheters are tunneled in a patient with subarachnoid hemorrhage. (B) Shows neuromonitoring catheters placed in the white matter on an axial computed tomography. EEG, electroencephalography; ICP, intracranial pressure; Temp, temperature.

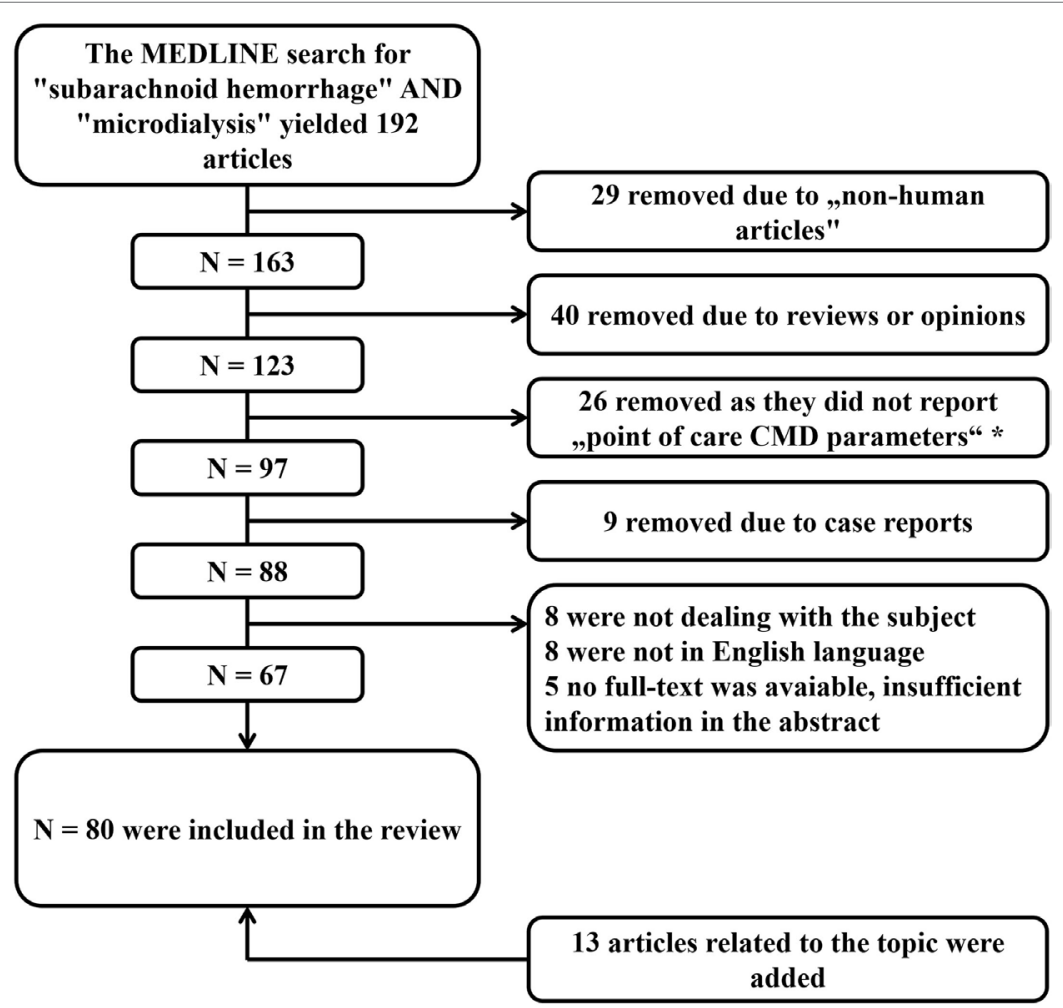

* point of care CMD parameters“ CMD-glucose, CMD-lactate, CMD-pyruvate, CMD-lactate-to-pyruvate ratio, CMD-glutamate and CMD-glycerol

FIGURE 2 | Literature search with selection of articles included in the review. CMD, cerebral microdialysis.

is pathophysiologically related to, but temporally separated from the subsequent occurrence of delayed cerebral ischemia (DCI). EBI is the result of the initial hemorrhage leading to a cascade of ischemic injury, global brain swelling and early mitochondrial dysfunction, as well as pressure-related side effects due to parenchymal hematoma or early hydrocephalus.

\section{Procedural Monitoring}

One of the most feared complications early after $\mathrm{SAH}$ is aneurysm rebleeding, with the highest risk of occurrence within the first $24 \mathrm{~h}$ (8). Importantly, in most studies, metabolic monitoring using CMD started after the aneurysm had been secured (time to monitoring is given in Tables 3-8). While no CMD data are 
TABLE 1 | Summary of brain metabolic patterns using CMD in SAH patients.

\begin{tabular}{|c|c|c|c|c|c|c|}
\hline & CMD-glucose & CMD-lactate & CMD-pyruvate & CMD-LPR & CMD-glutamate & CMD-glycerol \\
\hline $\begin{array}{l}\text { Acute focal neurological } \\
\text { deficits }\end{array}$ & $\downarrow$ to $\downarrow \downarrow$ & $\uparrow \uparrow$ & $\mathrm{n} / \mathrm{a}$ & $\uparrow \uparrow$ & $\uparrow \uparrow$ & $\begin{array}{l}\uparrow \uparrow, \text { mainly on } \\
\text { days } 1-2 \text { after } \\
\text { subarachnoid } \\
\text { hemorrhage }\end{array}$ \\
\hline Global cerebral edema & $\downarrow$ or no difference & $\uparrow$ & $\begin{array}{l}\downarrow \downarrow \text { or } \uparrow \text { (metabolic distress } \\
\text { or hypermetabolism) }\end{array}$ & $\uparrow \uparrow$ or $\uparrow$ & $\mathrm{n} / \mathrm{a}$ & $\mathrm{n} / \mathrm{a}$ \\
\hline Delayed cerebral ischemia & $\begin{array}{l}\downarrow \downarrow \text {, decreasing } \\
12-16 \mathrm{~h} \text { before } \mathrm{DCl}\end{array}$ & $\begin{array}{l}\uparrow \uparrow \text {, early, sensitive, but } \\
\text { not specific }\end{array}$ & $\begin{array}{l}\downarrow \text { to } \downarrow \downarrow \text {, rarely independently } \\
\text { reported }\end{array}$ & $\begin{array}{l}\uparrow \uparrow, \text { increasing } \\
12-16 \mathrm{~h} \text { before } \\
\mathrm{DCl}\end{array}$ & $\begin{array}{l}\uparrow \text { to } \uparrow \uparrow \text {, early } \\
\text { and sensitive }\end{array}$ & $\uparrow$ to $\uparrow \uparrow$ \\
\hline Mitochondrial dysfunction & Within normal range & $\uparrow \uparrow$ & Within normal range & $\uparrow$ to $\uparrow \uparrow$ & $\uparrow$ to $\uparrow \uparrow$ & $\uparrow$ to $\uparrow \uparrow$ \\
\hline Poor outcome & $\downarrow \downarrow$ & $\uparrow$ to $\uparrow \uparrow$, unspecific & $\begin{array}{l}\downarrow \downarrow \text {, no increase to normal } \\
\text { values }\end{array}$ & $\uparrow \uparrow$ & $\uparrow \uparrow$ & $\uparrow$ \\
\hline
\end{tabular}

A single arrow $(\uparrow / \downarrow)$ indicates increased or decreased values compared to normal levels or the control group. Double arrows ( $\uparrow / \downarrow \downarrow)$ indicate that values are above/below pathologic

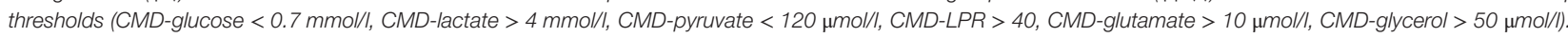

CMD, cerebral microdialysis; n/a, no data available.

available during coiling, several studies have investigated changes in cerebral metabolism during aneurysm surgery (Table 2) (9-13). Commonly used CMD sampling intervals between 10 and $60 \mathrm{~min}$ seem to be too imprecise to depict periprocedural changes in brain metabolism (9-11), although increases in CMD-LPR and CMD-glutamate levels following prolonged artery clipping and ischemic complications were reported $(9,10)$. The largest study, including 38 aneurysmal SAH patients, found no significant differences in metabolic markers of brain tissue ischemia during transient artery occlusion (median occlusion time was $14 \mathrm{~min}$ ) (11). In two patients with a prolonged occlusion time of more than $30 \mathrm{~min}$, a pronounced increase of CMD-glutamate was observed (11). The feasibility of rapid-sampling microdialysis (obtaining values up to every $30 \mathrm{~s}$ ) was investigated during temporal lobe retraction and transient artery occlusion (13). While metabolic changes reached a maximum after 3-10 min during temporal lobe retraction, increasing CMD-lactate and decreasing CMDglucose levels were observed until clip removal during artery occlusion (13). A higher sampling frequency in CMD monitoring may help to define a threshold for ischemia to prevent irreversible tissue damage during aneurysm obliteration.

\section{Post-Procedural Monitoring}

We identified nine studies focusing on the early phase after aneurysm treatment (Table 3) (14-22). In summary, CMD-LPR > 40 during the early phase is a sensitive marker for poor clinical grade on admission (18), radiological evidence of global cerebral edema (15), intracranial hypertension (19), and poor 3-month outcome (14). Critically, low levels of CMD-glucose were associated with acute neurological deficits (16). Trend analysis may indicate the clinical course with "normalization of CMD-parameters" being associated with clinical improvement and pathological evolution of brain metabolism with permanent neurological deficits (16).

\section{CMD and Acute Focal Neurological Deficits after SAH}

Most patients underwent aneurysm clipping. In a study including 26 poor-grade SAH patients $(68 \%$ Hunt and Hess grade
IV-V), CMD-LPR and CMD-glutamate were highest at the start of neuromonitoring, indicating metabolic distress (mean CMD-LPR > 40) and excitotoxicity, and significantly decreased thereafter (14). A higher CMD-LPR was associated with poor 3-month outcome (modified Rankin scale 4-6). CMD-glucose significantly decreased, however, did not reach critically low levels in this cohort with systemic glucose levels of 135-150 mg/ $\mathrm{dl}$ (7.5-8.3 mmol/l) (14). A study including $149 \mathrm{SAH}$ patients, of whom 89 (60\%) were admitted with good clinical grades (WFNS grades $\leq 3)$, reported higher CMD-LPR and CMD-lactate levels in poor-grade patients, already at the start of neuromonitoring, compared to good-grade patients (18). Moreover, higher CMDglycerol levels were reported in poor-grade patients, significantly decreasing over the first days (18).

In another study including $97 \mathrm{SAH}$ patients, the authors compared patients with and without acute focal neurological deficits immediately after SAH due to SAH-related parenchymal hematoma and/or perioperative/periinterventional ischemia. In patients with focal deficits, CMD-lactate, CMD-LPR, CMDglutamate, and CMD-glycerol were pathologically increased throughout the first week, whereas these parameters remained within normal range in patients without acute neurological deficits $(16,17)$. CMD-glucose levels were significantly lower in patients with acute focal deficits $(16,17)$, despite higher blood glucose concentrations (overall mean blood glucose levels were approximately $7.2-8.3 \mathrm{mmol} / \mathrm{l}=130-150 \mathrm{mg} / \mathrm{dl}$ ) (29). Regarding temporal dynamics, a trend toward normalization of CMD values was associated with clinical improvement, whereas further deterioration was associated with permanent neurological deficits in patients with acute focal deficits (16).

\section{CMD and Admission Global Cerebral Edema}

Two studies compared cerebral metabolic changes in patients with and without global cerebral edema (GCE) diagnosed by CT-imaging of the brain. Helbok et al. found an association between a higher frequency of metabolic crisis (significantly higher LPR, lower brain glucose levels) and GCE (15). Zetterling 
TABLE 2 | Brain metabolism during aneurysm surgery.

\begin{tabular}{|c|c|c|c|c|c|c|c|}
\hline Reference & Study type & $\begin{array}{c}\text { Number of } \\
\text { patients with } \\
\text { SAH }\end{array}$ & $\begin{array}{l}\text { Patient } \\
\text { characteristics }\end{array}$ & Monitoring period & Probe location & Study aim & Main microdialysis findings \\
\hline (13) & $\begin{array}{l}\text { Single-center, } \\
\text { prospective, } \\
\text { observational }\end{array}$ & 8 & $\begin{array}{l}\text { WFNS grade } \mathrm{I} n=5 \text {, } \\
\| n=3\end{array}$ & $\begin{array}{l}\text { Intraoperative. A CMD } \\
\text { catheter was inserted } \\
\text { immediately after } \\
\text { opening the dura }\end{array}$ & $\begin{array}{l}\text { Territory of the parent } \\
\text { artery of the aneurysm }\end{array}$ & $\begin{array}{l}\text { Detecting adverse metabolic } \\
\text { events during aneurysm surgery } \\
\text { using rapid-sampling } \\
\text { microdialysis }\end{array}$ & $\begin{array}{l}\text { During temporal lobe retraction, CMD-lactate } \\
\text { levels increased (+0.66 mmol//) and CMD- } \\
\text { glucose levels decreased }(-0.12 \mathrm{mmol} / \mathrm{l}) \text {. } \\
\text { The peak of these changes was observed } \\
\text { after } 3-10 \mathrm{~min} \text {, despite continued retraction. } \\
\text { During temporary artery clipping, CMD- } \\
\text { lactate levels increased }(+0.73 \mathrm{mmol} / \mathrm{l}) \\
\text { and CMD-glucose levels decreased } \\
(-0.14 \mathrm{mmol} / /) \text {. These changes reached their } \\
\text { maximum right before clip removal }\end{array}$ \\
\hline (10) & $\begin{array}{l}\text { Single-center, } \\
\text { prospective, } \\
\text { observational }\end{array}$ & $5 / 12$ & $\begin{array}{l}\text { "Preselected on the } \\
\text { basis of anticipated } \\
\text { difficulty in surgery" }\end{array}$ & Intraoperative & $\begin{array}{l}\text { Cortical, territory of } \\
\text { the parent artery of the } \\
\text { aneurysm }\end{array}$ & $\begin{array}{l}\text { Studying amino acid } \\
\text { concentrations during periods of } \\
\text { cerebral ischemia }\end{array}$ & $\begin{array}{l}\text { CMD-glutamate levels increased between } \\
2.7 \text { - and } 8.1 \text {-fold during ischemic } \\
\text { intraoperative complications. No statistical } \\
\text { analysis was performed }\end{array}$ \\
\hline (9) & $\begin{array}{l}\text { Single-center, } \\
\text { prospective, } \\
\text { observational }\end{array}$ & $10 / 15$ & $\mathrm{n} / \mathrm{a}$ & Intraoperative & $\begin{array}{l}\text { Cortical, territory of } \\
\text { the parent artery of the } \\
\text { aneurysm }\end{array}$ & $\begin{array}{l}\text { To assess metabolic changes } \\
\text { during temporary artery clipping }\end{array}$ & $\begin{array}{l}\text { The CMD-LPR ranged from } 32 \text { to } 65 \text {. } \\
\text { Clipping }<3 \text { min was not followed by an } \\
\text { increase in CMD-LPR ( } 42-43 \text { ). Prolonged } \\
\text { clipping was followed by a pronounced } \\
\text { increase in CMD-LPR in } 2 \text { cases ( } 24-50 \text { and } \\
60-70) \text {. No statistical analysis was performed }\end{array}$ \\
\hline (11) & $\begin{array}{l}\text { Single-center, } \\
\text { prospective, } \\
\text { observational }\end{array}$ & $38 / 46$ & $\begin{array}{l}\text { WFNS grade. Poor } \\
(\text { III, IV, V) in } 18 \\
\text { patients, } 7 \text { aneurysms } \\
\text { were larger than } \\
25 \mathrm{~mm}\end{array}$ & Intraoperative & $\begin{array}{l}\text { Frontal or parietal lobe } \\
\text { ipsilateral to the aneurysm }\end{array}$ & $\begin{array}{l}\text { To investigate potential episodes } \\
\text { of cerebral ischemia during } \\
\text { aneurysm surgery }\end{array}$ & $\begin{array}{l}\text { Temporary artery clipping (median duration } \\
14 \text { min) was not associated with significant } \\
\text { changes in brain metabolism. In } 2 \text { patients, } \\
\text { who post-operatively developed cerebral } \\
\text { infarction, clipping for longer than } 30 \text { min was } \\
\text { associated with a significant CMD-glutamate } \\
\text { increase ( } 2-25 \mu \mathrm{mol} / \mathrm{l} \text { in } 1 \text { patient) }\end{array}$ \\
\hline $\begin{array}{l}\text { (12) (abstract } \\
\text { only) }\end{array}$ & $\begin{array}{l}\text { Single-center, } \\
\text { prospective, } \\
\text { observational }\end{array}$ & $10 / 16$ & $\begin{array}{l}\text { "Complex aneurysm } \\
\text { surgery" }\end{array}$ & Intraoperative & $\mathrm{n} / \mathrm{a}$ & $\begin{array}{l}\text { To investigate cerebral metabolic } \\
\text { changes during temporary } \\
\text { internal carotid artery clipping }\end{array}$ & $\begin{array}{l}\text { Minimal decreases in brain tissue oxygen } \\
\text { tension were not associated with metabolic } \\
\text { changes, while more pronounced decreases } \\
\text { were associated with an increase in CMD- } \\
\text { LPR. Prolonged occlusions ( } 42 \text { min) were } \\
\text { associated with an increase in CMD- } \\
\text { glutamate levels. No statistical analysis was } \\
\text { performed }\end{array}$ \\
\hline
\end{tabular}

WFNS, world federation of neurological societies; CMD, cerebral microdialysis; n/a, data not available; LPR, lactate-to-pyruvate-ratio. 
TABLE 3 | The clinical use of CMD in the acute phase after SAH.

\begin{tabular}{|c|c|c|c|c|c|c|c|}
\hline Reference & Study type & $\begin{array}{l}\text { Number of } \\
\text { patients } \\
\text { with SAH }\end{array}$ & $\begin{array}{l}\text { Patient } \\
\text { characteristics }\end{array}$ & Monitoring period & Probe location & Study aim & Main microdialysis findings \\
\hline (14) & $\begin{array}{l}\text { Single-center, } \\
\text { prospective, } \\
\text { observational }\end{array}$ & 26 & $\begin{array}{l}\text { Hunt and Hess grade II } \\
n=2(7.7 \%), I I n=6 \\
(23.1 \%), I V n=2 \\
(7.7 \%), \vee n=16 \\
(61.5 \%)\end{array}$ & $\begin{array}{l}\text { Monitoring was started } 22 \mathrm{~h} \\
\text { (median) after SAH. Data } \\
\text { of the following } 144 \mathrm{~h} \text { are } \\
\text { reported }\end{array}$ & $\begin{array}{l}\text { Frontal, ipsilateral to the } \\
\text { aneurysm; classified as } \\
\text { normal-appearing or } \\
\text { perilesional brain tissue }\end{array}$ & $\begin{array}{l}\text { Describing the metabolic } \\
\text { profile during the early phase } \\
\text { after SAH }\end{array}$ & $\begin{array}{l}\text { Peak levels of CMD-glutamate, CMD-glucose, } \\
\text { and the CMD-LPR occurred within the first } 24 \mathrm{~h} \text { of } \\
\text { monitoring and decreased over time. } \\
\text { CMD-pyruvate concentrations increased } \\
\text { compared to baseline values. A higher CMD-LPR } \\
\text { was associated with poor outcome. Higher } \\
\text { CMD-IL-6 levels were associated with DCl and } \\
\text { poor outcome }\end{array}$ \\
\hline (15) & $\begin{array}{l}\text { Single-center, } \\
\text { prospective, } \\
\text { observational }\end{array}$ & 39 & $\begin{array}{l}\text { Hunt and Hess grade I } \\
+\| n=3(8 \%), I I I n=6 \\
(15 \%), I V n=12(31 \%), \\
\vee n=18(46 \%)\end{array}$ & $\begin{array}{l}\text { Data are reported for days } \\
2-10 \text { after SAH }\end{array}$ & $\begin{array}{l}\text { Frontal, contralateral to the } \\
\text { craniotomy in clipped patients; } \\
\text { non-dominant hemisphere } \\
\text { in diffuse SAH or ipsilateral } \\
\text { in lateralized SAH in coiled } \\
\text { patients }\end{array}$ & $\begin{array}{l}\text { Comparing brain metabolism } \\
\text { of patients with and without } \\
\text { GCE on admission }\end{array}$ & $\begin{array}{l}\text { Patients with GCE showed a higher CMD-LPR } \\
\text { and lower CMD-pyruvate and CMD-glucose levels } \\
\text { compared to those without. Episodes of } \\
\text { CMD-LPR }>40 \text { and metabolic crisis } \\
\text { (CMD-LPR }>40 \text { and CMD-glucose }<0.7 \text { mmol/l) } \\
\text { were more common in patients with GCE. } \\
\text { CMD-LPR }>40 \text { and metabolic crisis were } \\
\text { associated with poor outcome }\end{array}$ \\
\hline (16) & $\begin{array}{l}\text { Single-center, } \\
\text { prospective, } \\
\text { observational }\end{array}$ & 95 & $\begin{array}{l}\text { WFNS grade I } n=40 \\
(42 \%), \| I n=11 \\
(11.5 \%), I I I n=11 \\
(11.5 \%), I V n=20 \\
(21 \%), \vee n=13(14 \%)\end{array}$ & $\begin{array}{l}\text { Monitoring was started } \\
34 / 49 \text { (mean) hours after } \\
\text { SAH and maintained for } \\
183 / 132 \text { (mean) hours in } \\
\text { patients with/without acute } \\
\text { focal neurological deficits }\end{array}$ & $\begin{array}{l}\text { Vascular territory of the } \\
\text { aneurysm; insertion into } \\
\text { lesioned tissue was avoided }\end{array}$ & $\begin{array}{l}\text { Investigating brain } \\
\text { metabolism in patients } \\
\text { with/without acute focal } \\
\text { neurological deficits }\end{array}$ & $\begin{array}{l}\text { CMD-glutamate, CMD-glycerol, CMD-lactate } \\
\text { concentrations, and the CMD-LPR were higher } \\
\text { in patients with acute focal neurological deficits } \\
\text { compared to those without. A normalization } \\
\text { of values over time was concomitant with an } \\
\text { improving clinical condition, further deterioration } \\
\text { with permanent neurological deficits }\end{array}$ \\
\hline (17) & $\begin{array}{l}\text { Single-center, } \\
\text { prospective, } \\
\text { observational }\end{array}$ & 97 & $\begin{array}{l}\text { WFNS grade I } n=37 \\
(38 \%), \| n=13(13 \%), \\
\text { III } n=9(9 \%), I V n=20 \\
(21 \%), V n=18(19 \%)\end{array}$ & $\begin{array}{l}\text { Catheters were inserted } \\
\text { within } 72 \mathrm{~h} \text { after SAH. Data } \\
\text { are reported for days } 1-10 \\
\text { after SAH }\end{array}$ & $\begin{array}{l}\text { Vascular territory most likely } \\
\text { affected by vasospasm; } \\
\text { insertion into lesioned. tissue } \\
\text { was avoided }\end{array}$ & $\begin{array}{l}\text { Comparing brain metabolism } \\
\text { of patients with acute } \\
\text { neurological deficits and DCl } \\
\text { to asymptomatic patients }\end{array}$ & $\begin{array}{l}\text { In patients with acute focal neurological } \\
\text { deficits, the CMD-glucose concentration was } \\
\text { lower, whereas the CMD-lactate, CMD-LPR, } \\
\text { CMD-glutamate and CMD-glycerol levels were } \\
\text { significantly elevated compared to asymptomatic } \\
\text { and DCl patients }\end{array}$ \\
\hline (18) & $\begin{array}{l}\text { Single-center, } \\
\text { prospective, } \\
\text { observational }\end{array}$ & 149 & $\begin{array}{l}\text { WFNS grade } 0 n=3 \\
(2 \%), I n=53(36 \%), \| \\
n=16(11 \%), I I n=17 \\
(11 \%), I V n=33(22 \%), \\
\vee n=27(18 \%)\end{array}$ & $\begin{array}{l}\text { Monitoring was started } \\
\text { after aneurysm treatment } \\
\text { (mean } 24.7 \mathrm{~h} \text { after SAH) } \\
\text { and maintained for } 161.8 \mathrm{~h} \\
\text { (mean) }\end{array}$ & $\begin{array}{l}\text { Vascular territory of the } \\
\text { aneurysm; insertion into } \\
\text { lesioned tissue was avoided }\end{array}$ & $\begin{array}{l}\text { Investigating the relationship } \\
\text { between clinical disease } \\
\text { severity, brain metabolism } \\
\text { and outcome }\end{array}$ & $\begin{array}{l}\text { The concentrations of all parameters were higher } \\
\text { in high-grade (WFNS IV-V) compared to low- } \\
\text { grade patients, the differences were significant } \\
\text { for CMD-lactate, CMD-LPR and, during the first } \\
2 \text { days, CMD-glycerol }\end{array}$ \\
\hline (19) & $\begin{array}{l}\text { Single-center, } \\
\text { prospective, } \\
\text { observational }\end{array}$ & 36 & $\begin{array}{l}\text { All patients had a } \\
\text { WFNS grade of IV or V }\end{array}$ & $\begin{array}{l}\text { Surgery was performed } \\
44 / 30.7 \mathrm{~h} \text { after SAH in } \\
\text { patients with/without } \\
\text { intracranial hypertension. } \\
\text { Only patients with complete } \\
\text { datasets for the first } 7 \text { days } \\
\text { were included }\end{array}$ & $\begin{array}{l}\text { Vascular territory of the } \\
\text { aneurysm; insertion into } \\
\text { lesioned tissue was avoided }\end{array}$ & $\begin{array}{l}\text { To elucidate the impact of } \\
\text { intracranial hypertension on } \\
\text { brain metabolism }\end{array}$ & $\begin{array}{l}\text { Patients with intracranial hypertension } \\
\text { (ICP }>20 \mathrm{mmH} \text { ) had significantly lower levels of } \\
\mathrm{CMD} \text {-glucose and a higher CMD-LPR over the } \\
\text { first } 7 \text { days after SAH. CMD-glutamate levels were } \\
\text { significantly elevated in patients with high ICP on } \\
\text { day } 1\end{array}$ \\
\hline
\end{tabular}




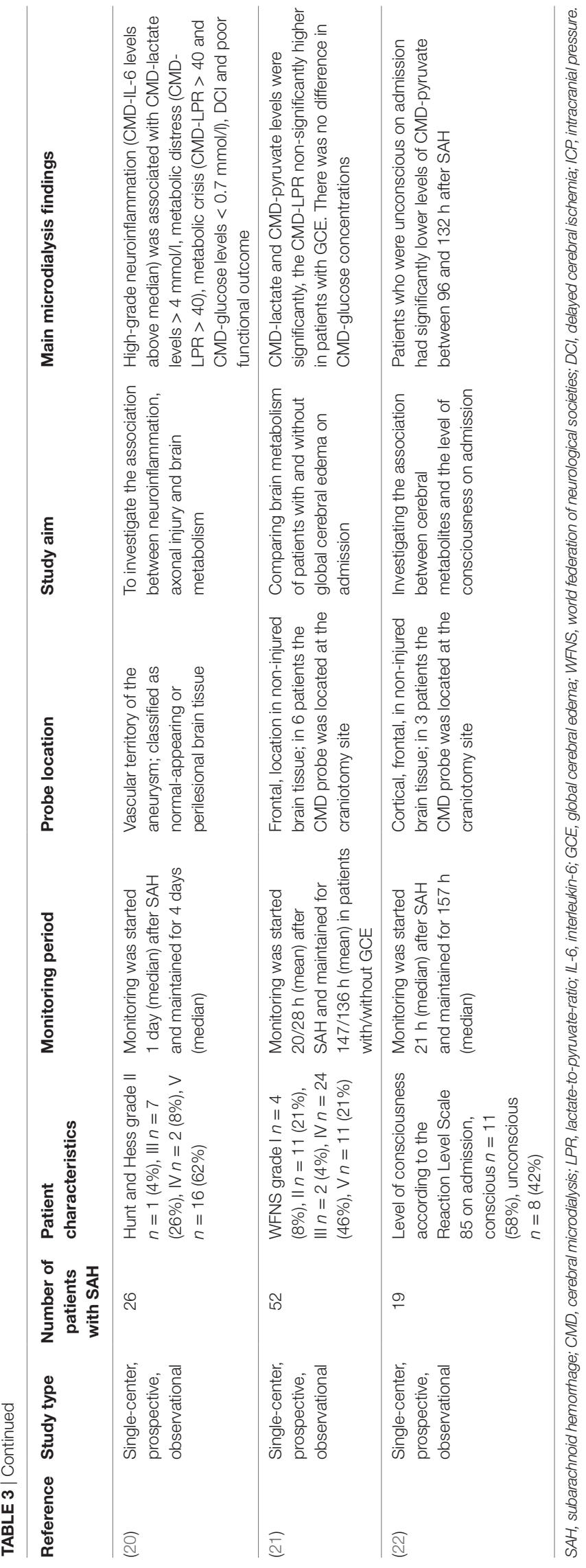

et al. described a pattern of cerebral hypermetabolism (higher lactate and pyruvate levels, no significant differences in LPR and glucose levels) in GCE patients (21). Despite this discrepancy, these findings indicate altered brain energy metabolism in SAH patients with GCE. Intracranial hypertension (ICP $>20 \mathrm{mmHg}$ ), often a result of brain edema or focal lesions, was associated with a pathologically elevated LPR $(>40)$ and significantly lower CMD-glucose levels (19).

\section{The Clinical Use of CMD as a Marker of Cerebral Hypoperfuison and DCI in SAH Patients}

Delayed cerebral ischemia occurs in up to $30 \%$ of SAH patients, mostly between 4 and 10 days after the hemorrhage, and was defined by an international group of experts as either clinical deterioration or cerebral infarction not attributable to other causes (83). In the literature published before 2010, we found a considerable heterogeneity in the definition of delayed ischemia after SAH. Detailed information on the definition used in individual trials is given in Table 4 .

Several studies investigated metabolic changes associated with parameters of cerebral perfusion, including CBF, CPP, and imaging surrogates. In summary, a negative correlation between CBF and CMD-lactate, CMD-LPR, CMD-glutamate, and CMDglycerol has been described, while CMD-pyruvate and CMDglucose are commonly positively correlated with $\operatorname{CBF}(25,31,32$, $35,38-40)$. Other studies focused on DCI and found increases in CMD-lactate and CMD-glutamate as early sensitive markers (17). Metabolic derangement with increasing CMD-LPR ( $>40)$ and decreasing CMD-glucose $(<0.7 \mathrm{mmol} / \mathrm{l})$ may occur up to $16 \mathrm{~h}$ before DCI onset $(26,32)$. In the following, we give detailed information on some studies, all studies are listed in Table 4.

Schmidt et al. found an association of CPP $<70 \mathrm{mmHg}$ with a higher incidence of metabolic crisis (CMD-LPR $>40$ and CMD-glucose levels $<0.7 \mathrm{mmol} / \mathrm{l}$ ) and further worsening of brain metabolism at lower CPP values (41). Similarly, a higher CMD-LPR and increased episodes of metabolic distress (CMD-LPR $>40$ ) were observed at a CPP $<60 \mathrm{mmHg}$ in another study including $19 \mathrm{SAH}$ patients (23). However, it is important to elaborate that a high CMD-LPR may also indicate metabolic distress in the absence of ischemia. In this regard, Jacobsen et al. defined an elevated LPR $(>30)$, together with pyruvate levels within normal range $(>70 \mu \mathrm{mol} / \mathrm{l})$ as mitochondrial dysfunction and found this pattern to be 7.5 -fold more common than metabolic changes indicative for cerebral ischemia (LPR $>30$ and CMD-pyruvate $<70 \mu \mathrm{mol} / \mathrm{l})$ (28). Mitochondrial dysfunction was moreover associated with higher levels of CMD-glucose and lower levels of CMD-glutamate and CMD-glycerol compared to ischemic episodes.

In poor-grade SAH patients requiring sedation and mechanical ventilation, neurological deterioration may not be detected. In these patients, CMD provides useful information on the metabolic state of the injured brain and may even indicate metabolic changes before DCI occurs. Sarrafzadeh et al. reported higher levels of CMD-lactate and CMD-glutamate in patients with DCI compared to those who did not develop DCI already on day 1 
TABLE 4 | The clinical use of CMD as a marker of cerebral hypoperfuison and DCI in SAH patients.

\begin{tabular}{|c|c|c|c|c|c|c|c|c|}
\hline Reference & Study type & $\begin{array}{l}\text { Number of } \\
\text { patients } \\
\text { with SAH }\end{array}$ & $\begin{array}{l}\text { Patient } \\
\text { characteristics }\end{array}$ & Monitoring period & Probe location & $\begin{array}{l}\text { Definition of ischemia/ } \\
\text { DCI }\end{array}$ & Study aim & Main microdialysis findings \\
\hline (23) & $\begin{array}{l}\text { Single-center, } \\
\text { prospective, } \\
\text { observational }\end{array}$ & 19 & $\begin{array}{l}\text { Hunt and Hess grade } \\
\begin{array}{l}\| n=2(10 \%), ~ I I \\
n=3(16 \%), I V n=10 \\
(53 \%), \vee n=4(21 \%)\end{array}\end{array}$ & $\begin{array}{l}\text { Monitoring was } \\
\text { started } 1.4 \text { days } \\
\text { (mean) after } \\
\text { SAH and was } \\
\text { maintained for } \\
5.8 \text { days (mean) }\end{array}$ & $\begin{array}{l}\text { Normal-appearing white } \\
\text { matter between anterior } \\
\text { and middle cerebral artery } \\
\text { territory on the side of } \\
\text { maximal pathology }\end{array}$ & $\begin{array}{l}\text { Neurological } \\
\text { worsening (GCS and } \\
\text { NIHSS), persistent } \\
\mathrm{P}_{\mathrm{b}} \mathrm{O}_{2}<15 \mathrm{mmHg} \text {, flow } \\
\text { velocity }>180 \mathrm{~cm} / \mathrm{s} \\
\text { (transcranial Doppler), } \\
\text { decreased alpha variability } \\
\text { on continuous EEG or } \\
\text { reduced blood flow on CT } \\
\text { perfusion }\end{array}$ & $\begin{array}{l}\text { To assess CMD-LPR } \\
\text { levels with respect to } \\
\text { established thresholds } \\
\text { of } \mathrm{CPP} \text { and } \mathrm{P}_{\mathrm{bt}} \mathrm{O}_{2}\end{array}$ & $\begin{array}{l}\text { The CMD-LPR was higher and } \\
\text { episodes of CMD-LPR }>40 \\
\text { occurred more often when the CPP } \\
\text { was }<60 \mathrm{mmHg} \text {. Brain tissue hypoxia } \\
\text { was associated with CMD-LPR }>40 \text {. } \\
\text { About } 50 \% \text { of } \mathrm{P}_{\mathrm{b}} \mathrm{O}_{2} \text { measurements } \\
\text { and } 80 \% \text { of } \mathrm{CPP} \text { measurements were } \\
\text { within normal range when the CMD- } \\
\mathrm{LPR} \text { was }>40 \text {. An LPR }>40 \text { was } \\
\text { associated with hospital mortality }\end{array}$ \\
\hline (24) & $\begin{array}{l}\text { Single-center, } \\
\text { prospective, } \\
\text { observational }\end{array}$ & 16 & $\begin{array}{l}\text { Hunt and Hess grade II } \\
n=13(81 \%), \text { III (19\%) }\end{array}$ & $\begin{array}{l}\text { All patients were } \\
\text { operated within } \\
1-3 \text { days after SAH }\end{array}$ & $\begin{array}{l}\text { Cortical, frontal or temporal, } \\
\text { ipsilateral to the aneurysm }\end{array}$ & $\begin{array}{l}\text { Vasospasm-related clinical } \\
\text { disturbances }\end{array}$ & $\begin{array}{l}\text { Associating CMD } \\
\text { findings with impending } \\
\text { ischemia }\end{array}$ & $\begin{array}{l}\text { Patients with } \mathrm{DCl} \text { showed increasing } \\
\text { levels of CMD-lactate and decreasing } \\
\text { levels of CMD-glucose. CMD-glutamate } \\
\text { levels were increased in the proximity of } \\
\text { infarcts on head CT }\end{array}$ \\
\hline (25) & $\begin{array}{l}\text { Single-center, } \\
\text { prospective, } \\
\text { observational }\end{array}$ & 6 & 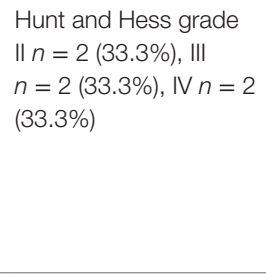 & $n / a$ & Cortical, frontal & $\begin{array}{l}\text { By PET: regional oxygen } \\
\text { extraction ratio }>125 \% \\
\text { and } \mathrm{CMRO}_{2} \geq 45 \% \\
\text { of the corresponding } \\
\text { contralateral region } \\
\text { or } \mathrm{CMRO}_{2}<45 \% \text { of } \\
\text { the corresponding } \\
\text { contralateral region }\end{array}$ & $\begin{array}{l}\text { To associate } \\
\text { brain metabolite } \\
\text { concentrations with } \\
\text { ischemia detected by } \\
\text { PET }\end{array}$ & $\begin{array}{l}\text { Ischemia, defined using the cerebral } \\
\text { metabolic rate of oxygen and oxygen } \\
\text { extraction ratio detected by PET, } \\
\text { was concomitant with high levels of } \\
\text { CMD-lactate, CMD-glutamate, and } \\
\text { CMD-LPR. No statistical analysis was } \\
\text { performed }\end{array}$ \\
\hline (26) & $\begin{array}{l}\text { Single-center, } \\
\text { prospective } \\
\text { observational }\end{array}$ & 32 & $\begin{array}{l}\text { Hunt and Hess grade } \\
\begin{array}{l}I+\| n=3(9 \%), ~ I I I \\
n=6(19 \%), I V n=9 \\
(28 \%), \vee n=14(44 \%)\end{array}\end{array}$ & $\begin{array}{l}\text { CMD data are } \\
\text { reported in relation } \\
\text { to head CT scans } \\
\text { between } 1 \text { and } \\
10 \text { days after the } \\
\text { hemorrhage }\end{array}$ & $\begin{array}{l}\text { White matter; frontal, } \\
\text { contralateral to the } \\
\text { craniotomy in clipped } \\
\text { patients; non-dominant } \\
\text { hemisphere in diffuse SAH } \\
\text { or ipsilateral in lateralized } \\
\text { SAH in coiled patients }\end{array}$ & $\begin{array}{l}\text { Clinical symptoms or new } \\
\text { infarcts on CT or MRI } \\
\text { attributable to vasospasm }\end{array}$ & $\begin{array}{l}\text { Comparing the } \\
\text { metabolic patterns } \\
\text { preceding head CT } \\
\text { scans with and without } \\
\text { new infarcts }\end{array}$ & $\begin{array}{l}\text { CMD-lactate levels and the CMD-LPR } \\
\text { significantly increased and CMD- } \\
\text { glucose concentrations significantly } \\
\text { decreased (to } 0.5 \mathrm{mmol} / \mathrm{l}) \text { when new } \\
\text { infarcts were detected on a head } \\
\text { CT scan. This was not observed in } \\
\text { contralateral (from the CMD probe) or } \\
\text { distant ( }>4 \mathrm{~cm} \text { ) infarction. Metabolic } \\
\text { crisis (CMD-LPR }>40 \text { and CMD- } \\
\text { glucose }<0.7 \mathrm{mmol} / \text { ) was more } \\
\text { common when new infarcts were } \\
\text { revealed }\end{array}$ \\
\hline (27) & $\begin{array}{l}\text { Single-center, } \\
\text { prospective } \\
\text { observational }\end{array}$ & 4 & $\begin{array}{l}\text { Hunt and Hess grade } \\
\qquad I n=2(50 \%), \text { III } n=1 \\
(25 \%), \text { IV } n=1(25 \%)\end{array}$ & $\begin{array}{l}\text { CMD was started } \\
\text { between } 12 \text { and } \\
28 \mathrm{~h} \text { after SAH and } \\
\text { maintained until } \\
\text { about } 200 \mathrm{~h} \text { after } \\
\text { SAH }\end{array}$ & Cortical, frontal & $\begin{array}{l}\text { Neurological signs and } \\
\text { neuro-imaging (CT/PET) }\end{array}$ & $\begin{array}{l}\text { Associating the } \\
\text { temporal dynamics of } \\
\text { cerebral CMD-glycerol } \\
\text { levels with ischemic } \\
\text { events }\end{array}$ & $\begin{array}{l}\text { Ischemic events were associated with } \\
\text { a pronounced increase in CMD-glycerol } \\
\text { levels (descriptive). In } 1 \text { patient without } \\
\text { ischemia CMD-glycerol remained } \\
\text { low after the peak immediately at the } \\
\text { start of monitoring. CMD-glycerol } \\
\text { levels correlated with CMD-LPR, } \\
\text { CMD-glutamate, and CMD-lactate } \\
\text { concentrations }\end{array}$ \\
\hline
\end{tabular}


TABLE 4 | Continued

\begin{tabular}{|c|c|c|c|c|c|c|c|c|}
\hline Reference & Study type & $\begin{array}{l}\text { Number of } \\
\text { patients } \\
\text { with SAH }\end{array}$ & $\begin{array}{l}\text { Patient } \\
\text { characteristics }\end{array}$ & Monitoring period & Probe location & $\begin{array}{l}\text { Definition of ischemia/ } \\
\text { DCI }\end{array}$ & Study aim & Main microdialysis findings \\
\hline (28) & $\begin{array}{l}\text { Single-center, } \\
\text { prospective, } \\
\text { observational }\end{array}$ & 55 & $\begin{array}{l}\text { Admission GCS } 15 \\
n=9(16 \%), 9-14 \\
n=20(36 \%),<9 \\
n=26(47 \%)\end{array}$ & $\mathrm{n} / \mathrm{a}$ & $\begin{array}{l}\text { Craniotomy site in patients } \\
\text { undergoing open surgery; } \\
\text { frontal in patients not } \\
\text { undergoing open surgery }\end{array}$ & $\begin{array}{l}\text { Biochemical: CMD- } \\
\text { LPR > } 30 \text { and CMD- } \\
\text { pyruvate }< \\
70 \mu \mathrm{mol} / \mathrm{l}\end{array}$ & $\begin{array}{l}\text { Proposing a metabolic } \\
\text { pattern suggestive } \\
\text { for mitochondrial } \\
\text { dysfunction }\end{array}$ & $\begin{array}{l}\text { The pattern of mitochondrial } \\
\text { dysfunction }(\mathrm{LPR}>30 \text { and } \\
\text { pyruvate }>70 \mu \mathrm{mol} / \mathrm{l}) \text { was more } \\
\text { common }(7.5 \text {-fold) than the } \\
\text { pattern of ischemia }(\mathrm{LPR}>30 \text { and } \\
\text { pyruvate }<70 \mu \mathrm{mol} / \mathrm{l}) \text { and associated } \\
\text { with higher levels of glucose and lower } \\
\text { levels of glutamate and glycerol }\end{array}$ \\
\hline (29) & $\begin{array}{l}\text { Single-center, } \\
\text { prospective, } \\
\text { observational }\end{array}$ & 170 & $\begin{array}{l}\text { WFNS grade } 0 n=3 \\
(2 \%), I n=58(34 \%), \\
\begin{array}{l}\| n=22(13 \%), \text { III } \\
n=18(11 \%), ~ I V \\
n=38(22 \%), \text { V } n=31 \\
(18 \%)\end{array}\end{array}$ & $\begin{array}{l}\text { Data are reported } \\
\text { for days } 1-7 \text { after } \\
\text { SAH }\end{array}$ & $\begin{array}{l}\text { Vascular territory of the } \\
\text { aneurysm; insertion into } \\
\text { lesioned tissue was avoided }\end{array}$ & Symptomatic vasospasm & $\begin{array}{l}\text { To compare systemic } \\
\text { and CMD-glucose } \\
\text { levels with respect to } \\
\text { acute focal neurological } \\
\text { deficits and } \mathrm{DCl}\end{array}$ & $\begin{array}{l}\text { Patients with acute neurological deficits } \\
\text { and patients developing DCI had higher } \\
\text { blood glucose levels on admission } \\
\text { and over the first } 7 \text { days compared to } \\
\text { asymptomatic patients, but significantly } \\
\text { lower CMD-glucose levels. The CMD- } \\
\text { LPR was highest in patients with acute } \\
\text { neurological deficits, followed by DCI } \\
\text { patients and asymptomatic patients }\end{array}$ \\
\hline (30) & $\begin{array}{l}\text { Single-center, } \\
\text { prospective } \\
\text { observational }\end{array}$ & 10 & $\begin{array}{l}\text { Hunt and Hess grade } \\
\begin{array}{l}\| n=2(20 \%), I I n=7 \\
(70 \%), \text { IV } n=1(10 \%)\end{array}\end{array}$ & $\begin{array}{l}\text { Catheters were } \\
\text { inserted } 1 \text { day } \\
\text { (median) after } \\
\text { SAH, CMD was } \\
\text { performed for } \\
4-11 \text { days (median) }\end{array}$ & $\begin{array}{l}\text { Cortical, frontal or temporal, } \\
\text { ipsilateral to the aneurysm }\end{array}$ & $\begin{array}{l}\text { Clinical deterioration } \\
\text { associated with cerebral } \\
\text { vasospasm }\end{array}$ & $\begin{array}{l}\text { Introducing a bedside } \\
\text { analyzer. Associating } \\
\text { metabolic patterns with } \\
\text { ischemia }\end{array}$ & 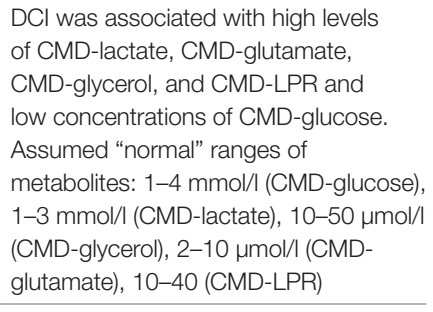 \\
\hline (31) & $\begin{array}{l}\text { Single-center, } \\
\text { retrospective, } \\
\text { observational }\end{array}$ & 21 & $\begin{array}{l}\text { Modified Fisher scale III } \\
n=6(29 \%), \text { IV } n=15 \\
(71 \%)\end{array}$ & $\begin{array}{l}\text { Time point of } \\
\text { monitoring start } \\
\text { not described. } \\
\text { Monitoring lasted } \\
10 \text { days in all } \\
\text { patients }\end{array}$ & $\begin{array}{l}\text { Frontal, ipsilateral to the } \\
\text { most prominent pathology, } \\
\text { intact brain tissue }\end{array}$ & $\mathrm{n} / \mathrm{a}$ & $\begin{array}{l}\text { Correlating the } \\
\text { concentrations of } \\
\text { cerebral metabolites } \\
\text { with CBF }\end{array}$ & $\begin{array}{l}\text { There was a positive correlation of CBF } \\
\text { (measured by a thermo-dilution probe) } \\
\text { with CMD-pyruvate and CMD-glucose } \\
\text { levels and a negative correlation with } \\
\text { CMD-lactate and CMD-glycerol levels } \\
\text { and the CMD-LPR }\end{array}$ \\
\hline (32) & $\begin{array}{l}\text { Single-center, } \\
\text { prospective } \\
\text { observational }\end{array}$ & 20 & $\begin{array}{l}\text { WFNS grade II } n=6 \\
(30 \%), \text { IV } n=2(10 \%), \\
\text { V } n=12(60 \%)\end{array}$ & $\begin{array}{l}\text { CMD sampling } \\
\text { was started } 14 \mathrm{~h} \\
\text { (median) after SAH } \\
\text { and maintained for } \\
8 \text { days (median) }\end{array}$ & $\begin{array}{l}\text { White matter, frontal } \\
\text { watershed of the non- } \\
\text { dominant hemisphere, } \\
\text { visually normal brain }\end{array}$ & $\begin{array}{l}\mathrm{CBF}<32.5 \mathrm{ml} / 100 \\
\mathrm{~g} / \mathrm{min} \text { and mean transit } \\
\text { time }>5.7 \mathrm{~s} \text { in } \mathrm{CT} \\
\text { perfusion }\end{array}$ & $\begin{array}{l}\text { Comparing metabolic } \\
\text { profiles between } \\
\text { patients with and } \\
\text { without cerebral } \\
\text { hypoperfusion } \\
\text { measured by CT }\end{array}$ & $\begin{array}{l}\text { The critical perfusion threshold was } \\
\text { defined as CBF }<32.5 \mathrm{ml} / 100 \mathrm{~g} / \mathrm{min} \\
\text { and mean transit time }>5.7 \mathrm{~s} \text {. Patients } \\
\text { with hypoperfusion had a significantly } \\
\text { higher CMD-LPR ( } 51 \mathrm{vs} \text {. } 31 \text { ) and } \\
\text { lower CMD-glucose levels }(0.64 \mathrm{vs} \text {. } \\
1.22 \mathrm{mmol} / \mathrm{l}) \text {. During the } 18 \mathrm{~h} \text { before } \\
\text { the perfusion CT was performed, there } \\
\text { was a significant increase in CMD-LPR } \\
\text { and decrease in CMD-glucose levels } \\
\text { in the hypoperfusion group, but not in } \\
\text { patients with normal CBF }\end{array}$ \\
\hline
\end{tabular}


TABLE 4 | Continued

\begin{tabular}{|c|c|c|c|c|c|c|c|c|}
\hline Reference & Study type & $\begin{array}{l}\text { Number of } \\
\text { patients } \\
\text { with SAH }\end{array}$ & $\begin{array}{l}\text { Patient } \\
\text { characteristics }\end{array}$ & Monitoring period & Probe location & $\begin{array}{l}\text { Definition of ischemia/ } \\
\text { DCI }\end{array}$ & Study aim & Main microdialysis findings \\
\hline (33) & $\begin{array}{l}\text { Single-center, } \\
\text { prospective } \\
\text { observational }\end{array}$ & 10 & $\begin{array}{l}\text { Hunt and Hess grade } \\
\begin{array}{l}\| n=3(30 \%), \\
(4 I I n=4)\end{array} \\
(40 \% n=3(30 \%)\end{array}$ & $\begin{array}{l}\text { Start time is not } \\
\text { exactly given } \\
\text { (figures indicate } \\
12-30 \mathrm{~h} \text { after } \mathrm{SAH} \text { ). } \\
\text { Monitoring lasted } \\
\text { 6-11 days (range) }\end{array}$ & Cortical, frontal & $\begin{array}{l}\text { CT findings and clinical } \\
\text { course }\end{array}$ & $\begin{array}{l}\text { To match CMD data } \\
\text { with CT findings, clinical } \\
\text { course and outcome }\end{array}$ & $\begin{array}{l}\text { CMD-lactate elevations were } \\
\text { frequently observed without obvious } \\
\text { cause, while CMD-LPR reflected } \\
\text { ischemia and, during days } 0-4 \text {, } \\
\text { correlated with outcome. In an } \\
\text { infracted area, CMD-glucose levels } \\
\text { fell to and remained at } 0 \text {. Zero-levels } \\
\text { of CMD-glucose were observed } \\
\text { more frequently in patients with } \\
\text { poor outcome. Patients with poor } \\
\text { outcome had significantly higher CMD- } \\
\text { glutamate levels }\end{array}$ \\
\hline (34) & $\begin{array}{l}\text { Single-center, } \\
\text { prospective, } \\
\text { observational }\end{array}$ & 18 & $\begin{array}{l}\text { WFNS grade I } n=4 \\
(22 \%), \| I n=4(22 \%), \\
\text { III } n=1(6 \%), I V n=6 \\
(33 \%), V n=2(17 \%)\end{array}$ & $\begin{array}{l}\text { CMD monitoring } \\
\text { started within } 24 \mathrm{~h} \\
\text { after admission. } \\
\text { Data were analyzed } \\
\text { on days 1-12 after } \\
\text { SAH }\end{array}$ & $\begin{array}{l}\text { Vascular territory of the } \\
\text { aneurysm }\end{array}$ & $\begin{array}{l}\text { New focal neurological } \\
\text { impairment or } \\
\text { decrease } \geq 2 \text { points in } \\
\text { GCS score for at least } 1 \mathrm{~h} \text {, } \\
\text { not attributable to other } \\
\text { causes }\end{array}$ & $\begin{array}{l}\text { Investigating an } \\
\text { association between } \\
\text { early onset pneumonia } \\
\text { and cerebral } \\
\text { metabolism }\end{array}$ & $\begin{array}{l}\text { Elevated lactate levels on day } 7 \text { were } \\
\text { associated with } \mathrm{DCl}\end{array}$ \\
\hline (35) & $\begin{array}{l}\text { Single-center, } \\
\text { prospective, } \\
\text { observational }\end{array}$ & 9 & $\begin{array}{l}\text { Hunt and Hess grade } \\
\text { In=2(22.2\%), II } \\
n=2(22.2 \%), \text { III } \\
n=2(22.2 \%), \text { IV } \\
n=2(22.2 \%), V n=1 \\
(11.1 \%)\end{array}$ & $\begin{array}{l}\text { Within } 72 \mathrm{~h} \text { of } \\
\text { admission }\end{array}$ & Cortical, right frontal lobe & $\begin{array}{l}\text { Neurologic deficit or } \\
\text { deterioration that could } \\
\text { not be explained by other } \\
\text { reasons }\end{array}$ & $\begin{array}{l}\text { Associating the } \\
\text { concentrations of } \\
\text { cerebral metabolites } \\
\text { with CBF }\end{array}$ & $\begin{array}{l}\text { Lower CBF, measured by Xenon-CT, } \\
\text { occurred together with higher levels } \\
\text { of CMD-glutamate and a higher } \\
\text { CMD-LPR. There was a descriptive } \\
\text { association between CMD-LPR }>25 \\
\text { and a CBF }<22 \mathrm{ml} / 100 \mathrm{~g} / \mathrm{min} \text {. No } \\
\text { statistical analyses were performed }\end{array}$ \\
\hline (36) & $\begin{array}{l}\text { Single-center, } \\
\text { prospective, } \\
\text { observational }\end{array}$ & 78 & $\begin{array}{l}\text { WFNS grade I } n=26 \\
(33 \%), I I n=11(14), I I I \\
n=9(12 \%), I V n=18 \\
(23 \%), V n=14(18 \%)\end{array}$ & $\begin{array}{l}\text { Monitoring was } \\
\text { started } 46 \mathrm{~h} \text { (mean) } \\
\text { after SAH and } \\
\text { maintained for } \\
155 \mathrm{~h} \text { (mean) }\end{array}$ & $\begin{array}{l}\text { White matter, vascular } \\
\text { territory most likely affected } \\
\text { by vasospasm }\end{array}$ & $\begin{array}{l}\text { Insidious onset of } \\
\text { confusion or appearance } \\
\text { of a focal neurological } \\
\text { deficit }\end{array}$ & $\begin{array}{l}\text { To assess the sensitivity } \\
\text { and specificity of CMD } \\
\text { for confirming DCl }\end{array}$ & $\begin{array}{l}\text { Baseline values did not differ between } \\
\text { patients with and without DCl. } \\
\text { Threshold values were set at } \\
\text { CMD-lactate }>4 \mathrm{mmol} / / \text { and } \\
\text { CMD-glutamate }>3 \mu \mathrm{mol} / \mathrm{l} \text {. CMD } \\
\text { showed a higher specificity for } \\
\text { confirming DCl than conventional } \\
\text { angiography and TCD }\end{array}$ \\
\hline (37) & $\begin{array}{l}\text { Single-center, } \\
\text { prospective } \\
\text { observational }\end{array}$ & 33 & $\begin{array}{l}\text { WFNS grade } 3.5 \\
\text { (median), } 1-5 \text { (range) }\end{array}$ & $\begin{array}{l}\text { Monitoring was } \\
\text { started } 29.5 \mathrm{~h} \\
\text { (mean) after SAH } \\
\text { and maintained for } \\
112 \mathrm{~h} \text { (mean) }\end{array}$ & $\begin{array}{l}\text { Cortical, frontal or temporal, } \\
\text { visually non-injured tissue }\end{array}$ & $\begin{array}{l}\text { Decrease in the level of } \\
\text { consciousness ( } \geq 1 \text { step } \\
\text { in the RLS score) or new } \\
\text { focal neurological deficit, } \\
\text { not due to other causes } \\
\text { but vasospasm }\end{array}$ & $\begin{array}{l}\text { Identifying a metabolic } \\
\text { pattern indicative of } \\
\text { ischemia }\end{array}$ & $\begin{array}{l}\text { Five hours of CMD-LPR }>40 \text { during } \\
\text { a } 10 \text {-h period were defined as } \\
\text { ischemic pattern. } 12 \text { episodes of this } \\
\text { pattern occurred, of which } 5 \text { were } \\
\text { attributable to early infarcts and } 6 \text { to } \\
\mathrm{DCl} \text {. Only } 6 \text { of } 15 \text { cases of DCl were } \\
\text { associated with this pattern, which, } \\
\text { in these cases, occurred } 16.7 \mathrm{~h} \\
\text { before DCl }\end{array}$ \\
\hline
\end{tabular}


TABLE 4 | Continued

\begin{tabular}{|c|c|c|c|c|c|c|c|c|}
\hline Reference & Study type & $\begin{array}{l}\text { Number of } \\
\text { patients } \\
\text { with SAH }\end{array}$ & $\begin{array}{l}\text { Patient } \\
\text { characteristics }\end{array}$ & Monitoring period & Probe location & $\begin{array}{l}\text { Definition of ischemia/ } \\
\text { DCI }\end{array}$ & Study aim & Main microdialysis findings \\
\hline (38) & $\begin{array}{l}\text { Single-center, } \\
\text { prospective, } \\
\text { observational }\end{array}$ & 7 & $\begin{array}{l}\text { Symptoms on } \\
\text { admission, } 3 \text { patients } \\
\text { (43\%) were described } \\
\text { as asymptomatic, } 4 \\
(57 \%) \text { suffered from } \\
\text { either aphasia or } \\
\text { hemiparesis }\end{array}$ & $\begin{array}{l}\text { Clipping and CMD } \\
\text { probe insertion } \\
\text { were performed } \\
\text { within } 24 \mathrm{~h} \text { after } \\
\text { SAH. The mean } \\
\text { monitoring time } \\
\text { was } 8.5 \text { days }\end{array}$ & $\begin{array}{l}\text { Vascular territory of the } \\
\text { aneurysm; insertion in } \\
\text { lesioned tissue was avoided }\end{array}$ & $\begin{array}{l}\text { New focal neurological } \\
\text { signs or deterioration in } \\
\text { level of consciousness, } \\
\text { excluding other causes } \\
\text { but vasospasm }\end{array}$ & $\begin{array}{l}\text { To associate PET } \\
\text { findings indicative of } \\
\text { hypoxia with CBF and } \\
\text { cerebral metabolism }\end{array}$ & $\begin{array}{l}\text { In regions with }{ }^{18} \mathrm{~F} \text {-FMISO uptake, a } \\
\text { PET marker of hypoxia, CMD-glutamate } \\
\text { levels were significantly higher } \\
\text { compared to regions without uptake. } \\
\text { No differences in energy metabolite } \\
\text { concentrations were observed }\end{array}$ \\
\hline (39) & $\begin{array}{l}\text { Single-center, } \\
\text { prospective } \\
\text { observational }\end{array}$ & 15 & $\begin{array}{l}\text { Neurological } \\
\text { symptoms, } 5 \text { patients } \\
\text { (33.3\%) were classified } \\
\text { as asymptomatic. } \\
10 \text { patients ( } 66.6 \%) \\
\text { suffered either from } \\
\text { aphasia (1), frontal lobe } \\
\text { dysfunction (2), paresis } \\
\text { (5) or coma (2) }\end{array}$ & $\begin{array}{l}\text { Monitoring was } \\
\text { started } 52.8 \mathrm{~h} \\
\text { (mean) after SAH } \\
\text { and maintained for } \\
201 / 211 \mathrm{~h} \text { (mean) } \\
\text { in patients with/ } \\
\text { without symptoms } \\
\text { of ischemia }\end{array}$ & $\begin{array}{l}\text { Brain parenchyma } \\
\text { most likely affected by } \\
\text { vasospasm }\end{array}$ & Neurological deficits & $\begin{array}{l}\text { To associate } \\
\text { brain metabolite } \\
\text { concentrations with } \\
\text { CBF and ischemia } \\
\text { measured by PET }\end{array}$ & $\begin{array}{l}\text { On the day of PET, levels of CMD- } \\
\text { lactate, CMD-glutamate, CMD-glycerol } \\
\text { and the CMD-LPR were significantly } \\
\text { higher in symptomatic patients. There } \\
\text { were strong inverse correlations } \\
\text { between CBF (measured by PET) and } \\
\text { CMD-glutamate and CMD-glycerol } \\
\text { levels }\end{array}$ \\
\hline (40) & $\begin{array}{l}\text { Single-center, } \\
\text { prospective } \\
\text { observational }\end{array}$ & 13 & $\begin{array}{l}\text { WFNS grade I } n=3 \\
(23 \%), \| n=2(15.5 \%), \\
\text { III } n=4(33 \%), \text { IV } \\
n=3(23 \%), V n=1 \\
(15.5 \%)\end{array}$ & $\begin{array}{l}\text { Monitoring was } \\
\text { started } 52.8 \mathrm{~h} \\
\text { (mean) after SAH } \\
\text { and maintained for } \\
201 \mathrm{~h} \text { (mean) }\end{array}$ & $\begin{array}{l}\text { White matter, vascular } \\
\text { territory most likely affected } \\
\text { by vasospasm; insertion in } \\
\text { lesioned tissue was avoided }\end{array}$ & $\begin{array}{l}\text { Worsening of headache or } \\
\text { focal neurological deficits } \\
\text { not present at admission, } \\
\text { between } 2 \text { and } 14 \text { days } \\
\text { after SAH, not attributable } \\
\text { to other causes }\end{array}$ & $\begin{array}{l}\text { Associating CMD } \\
\text { parameters with } \\
\text { symptoms of ischemia } \\
\text { and CBF }\end{array}$ & $\begin{array}{l}\text { 3-day medians were compared } \\
\text { between symptomatic (ischemic) and } \\
\text { asymptomatic intervals. The CMD-LPR, } \\
\mathrm{CMD} \text {-lactate, and CMD-glutamate } \\
\text { levels were higher during symptomatic } \\
\text { intervals. There were strong inverse } \\
\text { correlations between CBF (measured } \\
\text { by PET) and CMD-glutamate and } \\
\mathrm{CMD} \text {-glycerol levels. CMD-lactate } \\
\text { levels }>4 \mathrm{mmol} / \mathrm{l} \text { were an indicator of } \\
\text { critically low CBF }(<20 \mathrm{~m} / 100 \mathrm{~g} / \mathrm{min})\end{array}$ \\
\hline (17) & $\begin{array}{l}\text { Single-center, } \\
\text { prospective, } \\
\text { observational }\end{array}$ & 97 & $\begin{array}{l}\text { WFNS grade I } n=37 \\
(38 \%), \| n=13(13 \%), \\
\text { III } n=9(9 \%), \text { IV } \\
n=20(21 \%), \vee n=18 \\
(19 \%)\end{array}$ & $\begin{array}{l}\text { Catheters were } \\
\text { inserted within } 72 \mathrm{~h} \\
\text { after SAH. Data are } \\
\text { reported for days } \\
1-10 \text { after SAH }\end{array}$ & $\begin{array}{l}\text { Vascular territory most likely } \\
\text { affected by vasospasm; } \\
\text { insertion into lesioned } \\
\text { tissue was avoided }\end{array}$ & $\begin{array}{l}\text { Worsening of headache, } \\
\text { stiff neck, insidious onset } \\
\text { of confusion, disorientation } \\
\text { or drowsiness, or focal } \\
\text { neurological deficits, } \\
\text { between } 2 \text { and } 14 \text { days } \\
\text { after SAH, not attributable } \\
\text { to other causes }\end{array}$ & $\begin{array}{l}\text { Comparing brain } \\
\text { metabolism of patients } \\
\text { with acute neurological } \\
\text { deficits and DCl to } \\
\text { asymptomatic patients }\end{array}$ & $\begin{array}{l}\text { DCl patients had higher lactate and } \\
\text { glutamate concentrations on days } \\
1-8 \text { and a higher LPR on days 3-8 } \\
\text { compared with asymptomatic patients }\end{array}$ \\
\hline (41) & $\begin{array}{l}\text { Single-center, } \\
\text { prospective, } \\
\text { observational }\end{array}$ & 30 & $\begin{array}{l}\text { Hunt and Hess grade II } \\
+ \text { III } n=5(17 \%), I V \\
n=10(33 \%), V n=15 \\
(50 \%)\end{array}$ & $\begin{array}{l}\text { Monitoring was } \\
\text { started } 3 \text { days } \\
\text { (median) after SAH } \\
\text { and maintained for } \\
110 \mathrm{~h} \text { (median) }\end{array}$ & $\begin{array}{l}\text { Frontal, ipsilateral to } \\
\text { lateralized aneurysms, } \\
\text { right frontal lobe in case of } \\
\text { midline aneurysms }\end{array}$ & $\begin{array}{l}\text { Clinical deterioration } \\
\text { or cerebral infarction } \\
\text { attributable to vasospasm }\end{array}$ & $\begin{array}{l}\text { To identify the relation } \\
\text { between CPP } \\
\text { thresholds and brain } \\
\text { metabolic crisis }\end{array}$ & $\begin{array}{l}\text { Metabolic crisis (CMD-LPR }>40 \text { and } \\
\text { CMD-glucose levels } \leq 0.7 \mathrm{mmol} / \mathrm{l} \text { ) was } \\
\text { associated with a CPP }<70 \mathrm{mmHg} \text {, } \\
\text { Hunt and Hess grade } 5 \text {, intraventricular } \\
\text { or parenchymal hemorrhage, } \\
\text { hydrocephalus, ICP }>20 \mathrm{mmHg} \text { and } \\
\text { serum glucose levels }<6.6 \mathrm{mmol} / \mathrm{l} \text {. } \\
\text { Metabolic crisis was associated with } \\
\text { poor outcome }\end{array}$ \\
\hline
\end{tabular}


TABLE 4 | Continued

\begin{tabular}{|c|c|c|c|c|c|c|c|c|}
\hline Reference & Study type & $\begin{array}{l}\text { Number of } \\
\text { patients } \\
\text { with SAH }\end{array}$ & $\begin{array}{l}\text { Patient } \\
\text { characteristics }\end{array}$ & Monitoring period & Probe location & $\begin{array}{l}\text { Definition of ischemia/ } \\
\text { DCl }\end{array}$ & Study aim & Main microdialysis findings \\
\hline (42) & $\begin{array}{l}\text { Single-center, } \\
\text { prospective } \\
\text { observational }\end{array}$ & 18 & $\begin{array}{l}\text { Hunt and Hess grade } \\
\text { In=4 (22\%), II } n=4 \\
(22 \%), I I I n=7(39 \%), \\
\text { IV } n=3(17 \%)\end{array}$ & $\begin{array}{l}\text { Time point of } \\
\text { monitoring start } \\
\text { not described. } \\
\text { Monitoring was } \\
\text { maintained up to } \\
7 \text { days after SAH }\end{array}$ & $\begin{array}{l}\text { Subcortical, either } \\
\text { radiologically normal- } \\
\text { appearing brain tissue or } \\
\text { ischemic tissue indicated } \\
\text { by brain CT }\end{array}$ & $\begin{array}{l}\text { Infarction on cerebral CT } \\
\text { scans }\end{array}$ & $\begin{array}{l}\text { Comparing brain } \\
\text { metabolism between } \\
\text { patients without } \\
\text { ischemia and patients } \\
\text { suffering brain death }\end{array}$ & $\begin{array}{l}\text { In patients without evidence of cerebral } \\
\text { ischemia CMD-glucose and } \\
\text { CMD-pyruvate levels were significantly } \\
\text { higher and CMD-glutamate, CMD- } \\
\text { glycerol, and CMD-lactate levels and } \\
\text { the CMD-LPR were lower compared to } \\
\text { patients becoming brain dead. During } \\
\text { the time between brain death (complete } \\
\text { ischemia) and cessation of treatment, } \\
\text { CMD-glucose, and CMD-pyruvate were } \\
\text { not detectable and there was a further } \\
\text { increase of CMD-glutamate and } \\
\text { CMD-glycerol levels }\end{array}$ \\
\hline$(43)$ & $\begin{array}{l}\text { Single-center, } \\
\text { prospective } \\
\text { observational }\end{array}$ & 42 & $\begin{array}{l}\text { WFNS grade I } n=13 \\
(31 \%), \| I n=10(24 \%), \\
I I I n=3(7 \%), I V n=13 \\
(31 \%), \vee n=3(7 \%)\end{array}$ & $\begin{array}{l}\text { Time point of } \\
\text { monitoring start not } \\
\text { described. CMD } \\
\text { was performed for } \\
5 \text { days (mean) }\end{array}$ & $\begin{array}{l}\text { Cortical and white matter, } \\
\text { vascular territory of the } \\
\text { parent vessel of the } \\
\text { aneurysm }\end{array}$ & $\begin{array}{l}\text { Diagnosed by the } \\
\text { neurosurgeon on call }\end{array}$ & $\begin{array}{l}\text { Assessing the } \\
\text { predictive value of a } \\
\mathrm{CMD} \text { pattern for } \mathrm{DCl}\end{array}$ & $\begin{array}{l}\text { The pattern was defined as an increase } \\
\text { in CMD-LPR and lactate-to-glucose- } \\
\text { ratio }>20 \% \text {, followed by an increase } \\
\text { in CMD-glycerol levels }>20 \% \text {. In } 17 \\
\text { of } 18 \text { patients, in whom DCl occurred, } \\
\text { the pattern was found. It preceded the } \\
\text { event by } 11 \mathrm{~h} \text { (glycerol peak to DCl). } \\
\text { The ischemic pattern occurred in } 3 \\
\text { patients without DCl }\end{array}$ \\
\hline (44) & $\begin{array}{l}\text { Single-center, } \\
\text { prospective } \\
\text { observational }\end{array}$ & 60 & $\begin{array}{l}\text { WFNS grade I } n=20 \\
(33 \%), \text { II } n=9(15 \%), \\
\text { III } n=5(8 \%), \text { IV } \\
n=15(25 \%), \text { V } n=11 \\
(18 \%)\end{array}$ & $\begin{array}{l}\text { Monitoring was } \\
\text { started after } \\
\text { clipping, } 28 \mathrm{~h} \\
\text { (mean) after SAH. } \\
\text { Monitoring was } \\
\text { maintained for } \\
174 \mathrm{~h} \text { (mean) }\end{array}$ & $\begin{array}{l}\text { White matter, vascular } \\
\text { territory most likely affected } \\
\text { by vasospasm; insertion } \\
\text { into lesioned tissue was } \\
\text { avoided }\end{array}$ & $\begin{array}{l}\text { Symptomatic vasospasm } \\
\text { defined as insidious onset } \\
\text { of confusion or focal } \\
\text { neurological deficit }\end{array}$ & $\begin{array}{l}\text { To assess the predictive } \\
\text { ability of CMD regarding } \\
\text { DCl compared to } \\
\text { TCD and conventional } \\
\text { angiography }\end{array}$ & $\begin{array}{l}\text { Baseline values (first } 72 \mathrm{~h} \text { ) did not differ } \\
\text { between } \mathrm{DCl} \text { and non-DCl patients. } \\
\text { In DCl patients, CMD-glucose levels } \\
\text { decreased (64\%) and CMD-lactate and } \\
\text { CMD-glutamate levels increased ( } 112 \\
\text { and } 400 \% \text { ) thereafter. The pathological } \\
\text { threshold was defined as CMD-lactate } \\
\text { levels }>4 \mathrm{mmol} / / \text { and CMD-glutamate } \\
\text { levels }>3 \mu \mathrm{mol} / / \text { for } 6 \text { consecutive } \\
\text { hours. Using this pattern, CMD showed } \\
\text { a higher specificity than TCD and } \\
\text { angiography }\end{array}$ \\
\hline
\end{tabular}

SAH, subarachnoid hemorrhage; CMD, cerebral microdialysis; $L P R$, lactate-to-pyruvate-ratio; $C P P$, cerebral perfusion pressure; $P_{b i} \mathrm{O}_{2}$, brain tissue oxygen tension; $n / a$, data not available; $P E T$, positron emission tomography; WFNS, world federation of neurological societies; DCI, delayed cerebral ischemia; CBF, cerebral blood flow; FMISO, fluoromisonidazole; TCD, transcranial Doppler; CT, computed tomography; GCS, Glasgow coma scale; EEG, electroencephalography: MRI, magnetic resonance imaging: NIHSS, National Institutes of Health Stroke Scale; $\mathrm{CMRO}_{2}$, cerebral metabolic rate of oxygen; RLS, reaction level scale. 
and throughout the first week after the bleeding (17). A higher CMD-LPR was observed from day 3 on (17). This is in line with findings by Nilsson et al., who concluded that CMD-lactate and CMD-glutamate may be the earliest and most sensitive markers of ischemia, followed by the CMD-LPR and CMD-glycerol (30). Furthermore, lower brain glucose levels during the first 3 days after SAH were reported in DCI patients, despite higher blood glucose concentrations when compared to patients who did not develop DCI (29).

Changes in CMD parameters were observed even $12-16 \mathrm{~h}$ before the occurrence of DCI and included a significant increase in CMD-LPR to values $>40$ and decreases in CMD-glucose to levels $<0.7 \mathrm{mmol} / \mathrm{l}(26,32,37)$. At a comparable time point, also elevations of CMD-lactate, CMD-glutamate, and CMDglycerol were reported $(43,44)$. The sensitivity of the method is limited due to the local measurement. Therefore, ischemia occurring in brain tissue distant to the monitoring catheter may not be detected $(26,37)$. Lack of specificity results from metabolic distress secondary to non-ischemic CMD-LPR elevations and hyperglycolytic (non-ischemic) lactate increase $(28,72)$. Nevertheless, CMD had a higher specificity for predicting DCI than transcranial ultrasound and conventional angiography (44). Unfortunately, most studies do not report on the effect of current treatment strategies for DCI (induced hypertension, intraarterial spasmolysis). Sarrafzadeh et al. reported a decrease in CMD-glutamate levels, but no change in other parameters, associated with "triple-H therapy" (17). Further research focusing on metabolic changes following such interventions is surely warranted.

In summary, studies assessing CBF directly in the region around the CMD probe revealed a highly consistent metabolic pattern of increased CMD-lactate, CMD-glutamate, CMDglycerollevels, and CMD-LPR during episodes of hypoperfusion, whereas CMD-glucose and CMD-pyruvate levels were positively correlated with CBF. CMD-lactate and CMD-glutamate are early and sensitive markers of impending DCI, but lack of specificity. However, CMD parameters showed a higher specificity for predicting DCI than transcranial ultrasound and conventional angiography $(37,43,44)$. Regarding trend analyses, a CMD-LPR increase above 40 and decreasing CMD-glucose concentrations preceded the occurrence of delayed ischemia by several hours $(26,32)$; however, ischemia that occurred remote from the CMD probe or in the contralateral hemisphere was not detected (26).

\section{CMD in Monitoring Treatment Effects}

Several studies have investigated the effect of pharmacological and non-pharmacological interventions on cerebral metabolism as summarized in Table 5. Studied interventions included the treatment of intracranial hypertension, either with osmotherapy (45, 46), by cerebrospinal fluid drainage via external ventriculostomy (53), or by decompressive craniectomy $(49,50)$, fever treatment with diclofenac or targeted temperature management $(51,52,54)$, the management of anemia and administration of packed red blood cells $(47,48,52)$, and the administration of erythropoietin or verapamil $(55,56)$. The impact of enteral nutrition and insulin on brain metabolism will be discussed in the next chapter.

\section{CMD and Systemic Glucose Management}

There is still an ongoing debate on the optimal systemic glucose target in critically ill patients $(84,85)$. CMD-glucose levels represent the net effect of delivered glucose and glucose consumption. Little is known about the impact of glucose transport and diffusion in acutely brain injured patients.

Severe hyperglycemia $(>200 \mathrm{mg} / \mathrm{dl}=11.1 \mathrm{mmol} / \mathrm{l})$ is associated with poor outcome in $\mathrm{SAH}$ patients (86). Some studies investigated the association between systemic and brain interstitial glucose levels (Table 6). Oddo et al. described the brain metabolic profile during episodes of "low" ( $<4.4 \mathrm{mmol} /)$, "tight" (4.4-6.7 mmol/l), "intermediate" (6.8-10 mmol/l), and high blood glucose levels in a mixed population of neurocritical care patients, including 10 patients with SAH. Compared to intermediate systemic glucose levels, tight glycemic control was associated with lower CMD-glucose levels and more episodes of CMD-glucose $<0.7 \mathrm{mmol} / \mathrm{l}$, as well as a higher CMD-LPR and more episodes of metabolic crisis (CMD-LPR $>40$ and CMD-glucose concentrations $<0.7 \mathrm{mmol} / \mathrm{l})$. Metabolic crisis and CMD-glucose $<0.7 \mathrm{mmol} / \mathrm{l}$ were associated with higher hospital mortality (61). The significant association of systemicand CMD-glucose is supported by the results of other groups $(59,66)$; however, some studies indicate a poor correlation $(63$, 67), especially in the injured brain. Decreased CMD-glucose is moreover observed when delivery is reduced (i.e., reduction in $\mathrm{CBF}$ ) or under conditions of increased consumption (i.e., higher body temperature, seizures and the occurrence of cortical spreading depolarizations) $(66,78,82)$.

Pathologically low CMD-glucose levels $(<0.7$ or $<0.6 \mathrm{mmol} / \mathrm{l})$ were associated with poor outcome in SAH patients $(41,61,63)$. In the recent consensus statement on the use of $\mathrm{CMD}$, clinical experts suggest to intervene when pathologically low CMDglucose levels are detected (2). This attempt should only be made with respect to probe location (in healthy-appearing brain tissue on head computed tomography), baseline blood glucose levels, and in the absence of brain ischemia. Proposed interventions targeting higher systemic glucose levels include intravenous or enteral glucose administration and the reevaluation of insulin treatment (2).

While no data on intravenous glucose administration are available, three studies sought to investigate the impact of enteral feeding on cerebral metabolism. Schmidt et al. did not observe a direct relation between CMD-glucose levels and the energy content of the administered enteral nutrition (66). Other groups investigating the temporal association of enteral feeding and the metabolic profile revealed time-related increases in CMD-glucose levels not affecting other CMD parameters $(58,59)$. CMD-glucose levels even increased from critically low $(<0.7 \mathrm{mmol} / \mathrm{l})$ levels at baseline independent of probe location (59).

Insulin treatment was associated with a decrease of CMDglucose independent of serum glucose levels, resulting in a higher incidence of critically low CMD-glucose levels $(<0.6 \mathrm{mmol} / \mathrm{l})(64$, $67)$, especially under conditions of cerebral metabolic distress (LPR > 40) (66). Moreover, rapid reductions in serum glucose concentrations were associated with a decrease in CMD-glucose (57). In line with this, a higher serum glucose variability was associated with a higher rate of cerebral metabolic distress (60). In 
TABLE 5 | CMD in monitoring treatment effects in SAH patients.

Reference Study type Number of Patient characteristics

patients
with SAH

Monitoring period

Probe location

Study aim

Main microdialysis findings

\begin{tabular}{|c|c|c|c|c|c|c|}
\hline$(45)$ & $\begin{array}{l}\text { Single-center, } \\
\text { prospective, } \\
\text { interventional }\end{array}$ & 14 & $\mathrm{n} / \mathrm{a}$ & $\mathrm{n} / \mathrm{a}$ & $\begin{array}{l}\text { Frontal or parietal lobe } \\
\text { ipsilateral to the aneurysm }\end{array}$ & $\begin{array}{l}\text { To assess the impact } \\
\text { of hypertonic saline on } \\
\text { cerebral perfusion and } \\
\text { metabolism }\end{array}$ \\
\hline (46) & $\begin{array}{l}\text { Single-center, } \\
\text { prospective, } \\
\text { observational }\end{array}$ & $9 / 12$ & $\begin{array}{l}\text { Hunt and Hess grade } \\
5 \text { (median), } 4-5 \\
\text { (interquartile range) }\end{array}$ & $\begin{array}{l}\text { Monitoring was initiated at } \\
\text { day } 2 \text { (median) after SAH } \\
\text { and maintained for } 8 \text { days } \\
\text { (median) }\end{array}$ & $\begin{array}{l}\text { White matter, frontal, } \\
\text { hemisphere deemed at } \\
\text { greatest risk for secondary } \\
\text { injury }\end{array}$ & $\begin{array}{l}\text { To assess the impact of } \\
\text { intravenous mannitol on } \\
\text { cerebral metabolism }\end{array}$ \\
\hline
\end{tabular}

\begin{tabular}{llll}
\hline Single-center, & 34 & Hunt and Hess grade III & n/a \\
& $n=6(18 \%), I V n=12$ & \\
retrospective, & & $(35 \%), V n=16(47 \%)$ &
\end{tabular}

/a

observational (35\%), $\vee n=16(47 \%)$

\section{(48)}

$\begin{array}{lll}\begin{array}{l}\text { Single-center, } \\ \text { prospective, } \\ \text { observational }\end{array} & 15 \quad \begin{array}{l}\text { Hunt and Hess grade } \\ \mathrm{IV}+\mathrm{V} \text { in } 80 \% \text { of patients }\end{array} & \mathrm{n} / \mathrm{a} \\ & & \end{array}$

\begin{tabular}{|c|c|c|c|}
\hline (49) & $\begin{array}{l}\text { Single-center, } \\
\text { prospective, } \\
\text { observational }\end{array}$ & 18 & $\begin{array}{l}\text { WFNS grade I } n=3 \\
(17 \%), 11 \mid n=2(11 \%) \\
\text { IV } n=4(22 \%), \bigvee n=9\end{array}$ \\
\hline
\end{tabular}

(50\%)

\section{Catheters were inserted \\ 15/12 h (median) after SAH \\ for $164 / 180 \mathrm{~h}$ (median) \\ in patients with/without \\ craniectomy}

$\begin{array}{ll}\text { White matter, frontal, } & \text { Comparing the frequencies } \\ \text { hemisphere deemed at } & \text { of metabolic distress } \\ \text { greatest risk for secondary } & \text { between different } \\ \text { injury } & \text { hemoglobin levels }\end{array}$

injury
30 and 60 min after the infusion of hypertonic saline, the CMD-LPR decreased in 9 of 14 patients. Overall, this effect was not significant

Mannitol was administered due to an ICP crisis $>20 \mathrm{mmHg}$. The highest CMD-LPR was recorded at the time point of the start of the infusion (mean of 47). The CMD-LPR significantly decreased by $20 \%$ over $2 \mathrm{~h}, \mathrm{CMD}$-lactate and CMD-pyruvate levels decreased non-significantly, CMD-glucose remained unaffected

Compared to hemoglobin concentrations between 10 and $11 \mathrm{~g} / \mathrm{dll}$, episodes of CMD-LPR > 40 occurred 1.9 times more often when hemoglobin was between 9 and $10 \mathrm{~g} / \mathrm{dl}$, and 3.8 times more often when hemoglobin was below $9 \mathrm{~g} / \mathrm{dl}$ ( $45 \%$ of measurements showed CMD-LPR $>40$, respectively)

White matter, hemisphere Investigating the impact Over a 12-h period after a packed red blood cell deemed at greatest risk for of packed red blood infusion, no significant changes in cerebral metabolism secondary injury or right cell infusions on brain were observed, despite an increase in CPP and $\mathrm{P}_{\mathrm{bt}} \mathrm{O}_{2}$ frontal lobe; visually normal metabolism

tissue

\section{Vascular territory of the} aneurysm; insertion

into lesioned tissue was avoided

\section{To assess the impact of} decompressive craniectom (due to refractory intracranial hypertension) on levels of CMD-lactate, CMD-glutamate, CMD-glycerol, brain metabolism

Compared to a control group with normal ICP, patients

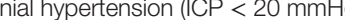
and CMD-LPR. Concentrations of CMD-glucose and CMD-pyruvate were higher and levels of CMDglycerol were lower in patients who underwent decompressive craniectomy compared to those who were treated conservatively. The metabolic pattern of CMD-LPR > 25, CMD-glycerol $>80 \mu \mathrm{mol} / \mathrm{l}$ and CMDglutamate $>10 \mu \mathrm{mol} / \mathrm{l}$ for $>6 \mathrm{~h}$ preceded the onset of refractory intracranial hypertension by $40 \mathrm{~h}$ (median)

Single-center, 182
prospective,
observational

WFNS grade $0 n=3$
$(2 \%), I n=61(37 \%), \|$
$n=23(14 \%)$, III $n=17$
$(10 \%)$, IV $n=35(21 \%)$, V $(10 \%), I V n=35$
Monitoring was started immediately after aneurys treatment $(23 / 13 \mathrm{~h}$

after $\mathrm{SAH}$, mean) and maintained for 169/172 (mean) in patients with/ without ICP intracranial hypertension

\section{Vascular territory of the} aneurysm; insertion into lesioned tissue was avoided

Investigating the impact of Higher CMD-LPR, CMD-glutamate, and CMDintracranial hypertension on glycerol levels and lower CMD-glucose levels were cerebral metabolism observed in patients with ICP $>20 \mathrm{mmHg}$. A metabolic pattern of $\mathrm{LPR}>25$, glutamate $>10 \mu \mathrm{mol} / \mathrm{I}$ and glycerol $>80 \mu \mathrm{mol} / \mathrm{l}$ preceded the first ICP increase $>20 \mathrm{mmHg}$. Decompressive craniectomy was associated with a decrease in CMD-glycerol and an increase in CMD-glutamate levels. Higher CMD-LPR and CMD-glutamate levels were associated with poor outcome 
TABLE 5 | Continued

\begin{tabular}{|c|c|c|c|c|c|c|c|}
\hline Reference & Study type & $\begin{array}{l}\text { Number of } \\
\text { patients } \\
\text { with SAH }\end{array}$ & Patient characteristics & Monitoring period & Probe location & Study aim & Main microdialysis findings \\
\hline (51) & $\begin{array}{l}\text { Single-center, } \\
\text { prospective, } \\
\text { observational }\end{array}$ & 18 & $\begin{array}{l}\text { Hunt and Hess grade } \\
\| n=2(11 \%), I I I n=4 \\
(22 \%), I V n=8(45 \%), V \\
n=4(22 \%)\end{array}$ & $\begin{array}{l}\text { Monitoring was initiated } \\
1 \text { day (median) after SAH. } \\
\text { Between } 37 \text { and } 168 \text { hourly } \\
\text { samples were obtained per } \\
\text { patient }\end{array}$ & $\begin{array}{l}\text { White matter, contralateral } \\
\text { to the maximal focal injury, } \\
\text { normal-appearing tissue }\end{array}$ & $\begin{array}{l}\text { To assess the impact of } \\
\text { induced normothermia on } \\
\text { cerebral metabolism }\end{array}$ & $\begin{array}{l}\text { When normothermia }\left(37^{\circ} \mathrm{C}\right) \text { was induced due to } \\
\text { refractory fever }\left(\geq 38.3^{\circ} \mathrm{C}\right) \text {, it was associated with } \\
\text { a decrease in CMD-LPR and fewer episodes of } \\
\text { metabolic distress }(C M D-L P R>40) \text {. Patients with } \\
\text { poor outcome had a higher CMD-LPR }\end{array}$ \\
\hline (52) & $\begin{array}{l}\text { Single-center, } \\
\text { prospective, } \\
\text { observational }\end{array}$ & 20 & $\begin{array}{l}\text { Hunt and Hess grade } \\
\text { II } n=2(10 \%), I I I n=4 \\
(20 \%), I V n=10(50 \%), V \\
n=4(20 \%)\end{array}$ & $\begin{array}{l}\text { Monitoring was started } \\
\text { with } 48 \mathrm{~h} \text { after SAH and } \\
\text { maintained for } 7 \text { days } \\
\text { (median) }\end{array}$ & $\begin{array}{l}\text { White matter, vascular } \\
\text { territory most likely } \\
\text { affected by vasospasm; } \\
\text { radiologically normal- } \\
\text { appearing tissue }\end{array}$ & $\begin{array}{l}\text { To associate hemoglobin } \\
\text { concentrations with cerebral } \\
\text { metabolism }\end{array}$ & $\begin{array}{l}\text { Hemoglobin concentrations }<9 \mathrm{~g} / \mathrm{dll} \text { were associated } \\
\text { with a higher absolute CMD-LPR and more episodes } \\
\text { of } L P R>40 \text { compared to higher hemoglobin levels }\end{array}$ \\
\hline (53) & $\begin{array}{l}\text { Single-center, } \\
\text { prospective, } \\
\text { observational }\end{array}$ & 33 & $\begin{array}{l}\text { WFNS grade } 3 \text { (median), } \\
1-5 \text { (range) }\end{array}$ & $\begin{array}{l}\text { CMD sampling was started } \\
29.5 \mathrm{~h} \text { (mean) after } \mathrm{SAH} \\
\text { and maintained for } 112 \mathrm{~h} \\
\text { (mean) }\end{array}$ & $\begin{array}{l}\text { Cortical, frontal or } \\
\text { temporal, non-injured brain } \\
\text { tissue }\end{array}$ & $\begin{array}{l}\text { To assess the relationship } \\
\text { between ICP, CPP and } \\
\text { cerebral metabolism }\end{array}$ & $\begin{array}{l}\text { CPP was positively correlated with CMD-pyruvate } \\
\text { levels. Episodes of ICP > } 10 \mathrm{mmHg} \text { were associated } \\
\text { with lower levels of CMD-pyruvate and higher levels } \\
\text { of CMD-lactate, CMD-pyruvate, and CMD-LPR. In } 3 \\
\text { patients, opening the ventricular drain was associated } \\
\text { with increasing CMD-pyruvate levels (descriptive) }\end{array}$ \\
\hline (54) & $\begin{array}{l}\text { Single-center, } \\
\text { prospective, } \\
\text { observational }\end{array}$ & 21 & $\begin{array}{l}\text { Hunt and Hess grade } \\
\begin{array}{l}\|+I I I n=6(29 \%), I V+V \\
n=13(71 \%)\end{array}\end{array}$ & $\begin{array}{l}\text { Monitoring was initiated at } \\
\text { day } 1 \text { (median) after SAH } \\
\text { and maintained for } 12 \\
\text { (median) days }\end{array}$ & $\begin{array}{l}\text { White matter, hemisphere } \\
\text { deemed at greatest risk for } \\
\text { secondary injury }\end{array}$ & $\begin{array}{l}\text { To assess the impact of } \\
\text { intravenous diclofenac on } \\
\mathrm{CPP}, \mathrm{P}_{\mathrm{bt}} \mathrm{O}_{2} \text { and cerebral } \\
\text { metabolism }\end{array}$ & $\begin{array}{l}\text { Despite a decrease of body temperature, CPP and } \\
\mathrm{Pbt}_{\mathrm{b}} \text {, no changes in cerebral metabolism were } \\
\text { observed }\end{array}$ \\
\hline (55) & $\begin{array}{l}\text { Single-center, } \\
\text { prospective, } \\
\text { randomized, } \\
\text { controlled, } \\
\text { double-blind }\end{array}$ & $\begin{array}{l}54 \text { (35 with } \\
\text { CMD) }\end{array}$ & $\begin{array}{l}\text { WFNS grade I } n=22 \\
(41 \%), \| I n=5(9 \%), I I I \\
n=1(2 \%), I V n=16 \\
(30 \%), V n=10(18 \%)\end{array}$ & $\begin{array}{l}\text { Data are reported for days } \\
1-14 \text { after SAH }\end{array}$ & $\begin{array}{l}\text { Vascular territory of the } \\
\text { aneurysm }\end{array}$ & $\begin{array}{l}\text { To study the efficacy and } \\
\text { safety of EPO in SAH } \\
\text { patients }\end{array}$ & $\begin{array}{l}\text { The administration of EPO was associated with higher } \\
\text { CMD-glycerol levels. No differences in other CMD } \\
\text { parameters were observed }\end{array}$ \\
\hline (56) & $\begin{array}{l}\text { Single-center, } \\
\text { prospective, } \\
\text { observational }\end{array}$ & 11 & $\begin{array}{l}\text { Hunt and Hess grade } \\
\text { III } n=3(27 \%), I V n=2 \\
(18 \%), \vee n=6(55 \%)\end{array}$ & $\begin{array}{l}\text { Measurements were } \\
\text { performed between after } \\
4-14 \text { days (range) after } \\
\text { SAH }\end{array}$ & $\begin{array}{l}\text { White matter, frontal } \\
\text { watershed, ipsilateral } \\
\text { to the aneurysm or } \\
\text { contralateral to the } \\
\text { craniotomy in clipped } \\
\text { patients }\end{array}$ & $\begin{array}{l}\text { To investigate the impact } \\
\text { of intraarterial verapamil on } \\
\text { brain metabolism }\end{array}$ & $\begin{array}{l}\text { There was a significant increase in CMD-glucose levels } \\
9 \mathrm{~h} \text { after the administration of intraarterial verapamil } \\
(1.2-1.53 \mathrm{mmol} / \mathrm{l}) \text {. No significant changes in other } \\
\mathrm{CMD} \text { parameters were observed }\end{array}$ \\
\hline
\end{tabular}

n/a, data not available; CMD, cerebral microdialysis; $L P R$, lactate-to-pyruvate-ratio; $S A H$, subarachnoid hemorrhage; $C P P$, cerebral perfusion pressure; $P_{b i} O_{2}$, brain tissue oxygen tension; ICP, intracranial pressure; EPO, erythropoietin. 
TABLE 6 | CMD and systemic glucose management in SAH patients.

\begin{tabular}{|c|c|c|c|c|c|c|c|}
\hline Reference & Study type & $\begin{array}{l}\text { Number of } \\
\text { patients } \\
\text { with SAH }\end{array}$ & $\begin{array}{l}\text { Patient } \\
\text { characteristics }\end{array}$ & Monitoring period & Probe location & Study aim & Main microdialysis findings \\
\hline$(57)$ & $\begin{array}{l}\text { Single ceter, } \\
\text { prospective, } \\
\text { observational }\end{array}$ & 28 & $\begin{array}{l}\text { Hunt and Hess grade } \\
\text { III } n=6(21 \%), \text { IV } n=8 \\
(29 \%), \vee n=14(50 \%)\end{array}$ & $\begin{array}{l}\text { Monitoring was initiated } \\
\text { on day } 2 \text { (median) after } \\
\text { SAH and maintained } \\
\text { for } 6 \text { days (median) }\end{array}$ & $\begin{array}{l}\text { White matter, frontal, tissue } \\
\text { at risk or contralateral to the } \\
\text { craniotomy }\end{array}$ & $\begin{array}{l}\text { To assess the relationship } \\
\text { between rapid reductions } \\
\text { in serum glucose and } \\
\text { brain metabolism }\end{array}$ & $\begin{array}{l}\text { Reductions in serum glucose by } 25 \% \text { (within normal range) } \\
\text { were independently associated with consecutive metabolic } \\
\text { crisis (CMD-LPR > } 40 \text { and CMD-glucose }<0.7 \text { ) and } \\
\text { increasing CMD-LPR. There was a concomitant decrease in } \\
\text { CMD-glucose and CMD-pyruvate. A higher CMD-LPR was } \\
\text { associated with hospital mortality }\end{array}$ \\
\hline (58) & $\begin{array}{l}\text { Single ceter, } \\
\text { prospective, } \\
\text { observational }\end{array}$ & 12 & $\begin{array}{l}\text { Glasgow coma scale } \\
\text { score 5-7 (range) }\end{array}$ & $\begin{array}{l}\text { Measurements took } \\
\text { place between } 1 \text { and } \\
5 \text { days after SAH }\end{array}$ & Cortical, right frontal lobe & $\begin{array}{l}\text { To investigate the impact } \\
\text { of enteral nutrition on } \\
\text { cerebral metabolism }\end{array}$ & $\begin{array}{l}\text { CMD-glucose levels significantly increased following the } \\
\text { first bolus of enteral nutrition }(2.5-3.7 \mathrm{mmol} / \mathrm{l}) \text {. No changes } \\
\text { in CMD-lactate, CMD-pyruvate, CMD-glutamate, or CMD- } \\
\text { glycerol were observed. No insulin was used during the } \\
\text { measurements }\end{array}$ \\
\hline (59) & $\begin{array}{l}\text { Single ceter, } \\
\text { prospective, } \\
\text { observational }\end{array}$ & 17 & $\begin{array}{l}\text { Hunt and Hess grade } \\
\begin{array}{l}\| n=2(12 \%), I I I n=6 \\
(35 \%), I V n=2(12 \%) \\
\vee n=7(41 \%)\end{array}\end{array}$ & $\begin{array}{l}\text { Measurements took } \\
\text { place between } 3 \text { and } \\
22 \text { days after SAH }\end{array}$ & $\begin{array}{l}\text { White matter, hemisphere } \\
\text { deemed at greatest risk for } \\
\text { secondary injury, classified } \\
\text { as normal-appearing or } \\
\text { perilesional brain tissue }\end{array}$ & $\begin{array}{l}\text { To investigate the impact } \\
\text { of enteral nutrition on } \\
\text { cerebral glucose levels }\end{array}$ & $\begin{array}{l}\text { Enteral nutrition significantly increased CMD-glucose levels } \\
(1.59-2.03 \mathrm{mmol} / /) \text { with a delay of } 3 \mathrm{~h} \text {. This increase was } \\
\text { independent of insulin administration, absolute levels of } \\
\text { serum glucose, evidence of cerebral metabolic distress, and } \\
\text { microdialysis probe location. Also critically low CMD-glucose } \\
\text { concentrations were increased. There was a significant } \\
\text { association between serum and CMD-glucose levels }\end{array}$ \\
\hline (60) & $\begin{array}{l}\text { Single ceter, } \\
\text { prospective, } \\
\text { observational }\end{array}$ & 28 & 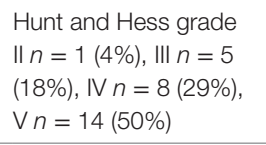 & $\begin{array}{l}\text { Monitoring was started } \\
2 \text { days (median) after } \\
\text { SAH and maintained } \\
\text { for } 6 \text { days (median) }\end{array}$ & $\begin{array}{l}\text { White matter, frontal, } \\
\text { hemisphere deemed at } \\
\text { greatest risk for secondary } \\
\text { injury }\end{array}$ & $\begin{array}{l}\text { To investigate the impact } \\
\text { of blood glucose variability } \\
\text { on cerebral metabolism }\end{array}$ & $\begin{array}{l}\text { A higher systemic glucose variability, defined as the SD of } \\
\text { measured concentrations per day, was associated with } \\
\text { a higher risk of developing at least one episode of CMD- } \\
\text { LPR }>40 \text { per day }\end{array}$ \\
\hline (61) & $\begin{array}{l}\text { Single ceter, } \\
\text { prospective, } \\
\text { observational }\end{array}$ & $10 / 20$ & $\begin{array}{l}\text { GCS score } 7 \text { (median), } \\
3-10 \text { (range) }\end{array}$ & $\begin{array}{l}\text { CMD monitoring } \\
\text { was started } 45 \mathrm{~h} \\
\text { (median) after } \mathrm{SAH} \text { and } \\
\text { maintained for } 96 \mathrm{~h} \\
\text { (median) }\end{array}$ & $\begin{array}{l}\text { Frontal, near the area of } \\
\text { lesioned tissue or right } \\
\text { frontal lobe in patients with } \\
\text { diffuse injury }\end{array}$ & $\begin{array}{l}\text { Investigating the impact of } \\
\text { tight glycemic control on } \\
\text { cerebral metabolism }\end{array}$ & $\begin{array}{l}\text { Blood glucose levels were defined as "tight" (4.4-6.7 mmol/) } \\
\text { or "intermediate" (6.8-10 mmo//). Tight blood glucose was } \\
\text { associated with lower levels of CMD-glucose, more episodes } \\
\text { of CMD-glucose }<0.7 \mathrm{mmol} / / \text {, higher CMD-LPR and a more } \\
\text { frequent occurrence of metabolic crisis (CMD-LPR }>40 \text { and } \\
\text { CMD-glucose levels }<0.7 \mathrm{mmo} / /) \text {. Low CMD-glucose levels and } \\
\text { metabolic crisis were associated with higher hospital mortality }\end{array}$ \\
\hline (62) & $\begin{array}{l}\text { Single ceter, } \\
\text { prospective, } \\
\text { observational }\end{array}$ & 178 & $\begin{array}{l}\text { WFNS grade I } n=65 \\
(37 \%), I I n=22(12 \%) \\
\text { III } n=20(11 \%), I V \\
n=36(20 \%), V n=35 \\
(20 \%)\end{array}$ & $\begin{array}{l}\text { CMD was performed } \\
\text { on days } 1-7 \text { after SAH }\end{array}$ & $\begin{array}{l}\text { Vascular territory of the } \\
\text { aneurysm; insertion into } \\
\text { lesioned tissue was avoided }\end{array}$ & $\begin{array}{l}\text { To investigate the } \\
\text { associations between } \\
\text { hyperglycemia, cerebral } \\
\text { metabolism and outcome }\end{array}$ & $\begin{array}{l}\text { CMD-glucose levels were higher during serum } \\
\text { glucose }>7.8 \mathrm{mmol} / \mathrm{l} \text {. No differences in other microdialysis } \\
\text { parameters were observed }\end{array}$ \\
\hline (63) & $\begin{array}{l}\text { Single ceter, } \\
\text { prospective, } \\
\text { observational }\end{array}$ & 28 & $\begin{array}{l}\text { WFNS grade I } n=8 \\
(29 \%), \| I n=6(21 \%) \\
\text { III } n=3(11 \%), I V n=6 \\
(21 \%), \bigvee n=5(18 \%)\end{array}$ & $\begin{array}{l}\text { Monitoring was initiated } \\
22.2 \mathrm{~h} \text { (mean) after } \\
\text { SAH and maintained } \\
\text { for } 195.4 \mathrm{~h} \text { (mean) }\end{array}$ & $\begin{array}{l}\text { Vascular territory of the } \\
\text { aneurysm; insertion into } \\
\text { lesioned tissue was avoided }\end{array}$ & $\begin{array}{l}\text { To investigate the impact } \\
\text { of hyperglycemia on } \\
\text { cerebral metabolism }\end{array}$ & $\begin{array}{l}\text { During episodes of blood glucose > } 140 \mathrm{mg} / \mathrm{dll} \text {, CMD-lactate } \\
\text { and CMD-pyruvate concentrations increased, the CMD-LPR } \\
\text { remained stable, and CMD-glutamate levels decreased. } \\
\text { Serum glucose concentrations did not differ during episodes } \\
\text { of high ( }>2.6 \mathrm{mmol} / \mathrm{l}) \text { and low }(<0.6 \mathrm{mmo} / \mathrm{l}) \mathrm{CMD} \text {-glucose } \\
\text { concentrations. During episodes of low CMD-glucose, } \\
\text { CMD-lactate, CMD-glutamate, CMD-glycerol levels, and the } \\
\text { CMD-LPR were elevated. Low CMD-glucose during blood } \\
\text { glucose }>140 \mathrm{mg} / \text { dl was associated with poor outcome }\end{array}$ \\
\hline
\end{tabular}


TABLE 6 | Continued

\begin{tabular}{|c|c|c|c|c|c|c|c|}
\hline Reference & Study type & $\begin{array}{l}\text { Number of } \\
\text { patients } \\
\text { with SAH }\end{array}$ & $\begin{array}{l}\text { Patient } \\
\text { characteristics }\end{array}$ & Monitoring period & Probe location & Study aim & Main microdialysis findings \\
\hline (64) & $\begin{array}{l}\text { Single ceter, } \\
\text { prospective, } \\
\text { observational }\end{array}$ & 31 & $\begin{array}{l}\text { WFNS grade I } n=9 \\
(29 \%), \| n=6(19 \%), \\
\text { III } n=3(10 \%), \text { IV } n=6 \\
(19 \%), V n=7(23 \%)\end{array}$ & $\begin{array}{l}\text { The mean duration } \\
\text { of monitoring was } \\
\text { 192/295 } \mathrm{h} \text { in patients } \\
\text { with/without insulin. } \\
\text { Data are reported for } \\
\text { days 1-10 after SAH }\end{array}$ & $\begin{array}{l}\text { Vascular territory of the } \\
\text { aneurysm; insertion into } \\
\text { lesioned tissue was avoided }\end{array}$ & $\begin{array}{l}\text { To investigate the impact } \\
\text { of intravenous insulin on } \\
\text { cerebral metabolism }\end{array}$ & $\begin{array}{l}\text { CMD-glucose levels, but not serum glucose levels, } \\
\text { decreased significantly } 3 \mathrm{~h} \text { after the start of the insulin } \\
\text { infusion. Episodes of low CMD-glucose }(<0.6 \mathrm{mmol} / \mathrm{l}) \text { were } \\
\text { (non-significantly) more common in patients who received } \\
\text { insulin. CMD-lactate and CMD-pyruvate levels did not } \\
\text { change, CMD-glycerol concentrations slightly increased, and } \\
\text { CMD-glutamate levels decreased after the start of insulin } \\
\text { treatment }\end{array}$ \\
\hline (65) & $\begin{array}{l}\text { Single-center, } \\
\text { prospective, } \\
\text { observational }\end{array}$ & 24 & $\begin{array}{l}\text { WFNS grade I } n=5 \\
(21 \%), \| I n=4(17 \%), \\
\text { III } n=2(8 \%), I V n=6 \\
(25 \%), \bigvee n=7(29 \%)\end{array}$ & $\begin{array}{l}\text { Data were collected on } \\
\text { days } 1-10 \text { after SAH }\end{array}$ & $\begin{array}{l}\text { Vascular territory of the } \\
\text { aneurysm; insertion into } \\
\text { lesioned tissue was avoided }\end{array}$ & $\begin{array}{l}\text { To investigate the long- } \\
\text { term effect of insulin on } \\
\text { cerebral metabolism }\end{array}$ & $\begin{array}{l}\text { Median daily CMD-glucose levels decreased after the } \\
\text { initiation of insulin treatment and were significantly lower, } \\
\text { compared to baseline, } 4 \text { days after insulin start. A significant } \\
\text { increase in CMD-glycerol levels was observed } 1 \text { day after } \\
\text { insulin start, which was not significant thereafter. CMD- } \\
\text { glutamate levels significantly decreased over time }\end{array}$ \\
\hline (66) & $\begin{array}{l}\text { Single ceter, } \\
\text { retrospective, } \\
\text { observational }\end{array}$ & 50 & $\begin{array}{l}\text { Hunt and Hess grade } \\
\text { II } n=3(6 \%), \text { III } n=7 \\
(14 \%), \text { IV } n=15(30 \%), \\
\vee n=25(50 \%)\end{array}$ & $\begin{array}{l}\text { Monitoring was started } \\
2 \text { days (median) after } \\
\text { SAH and maintained } \\
\text { for } 108 \mathrm{~h} \text { (mean) }\end{array}$ & $\begin{array}{l}\text { Normal-appearing white } \\
\text { matter }\end{array}$ & $\begin{array}{l}\text { To elucidate the relations } \\
\text { between enteral nutrition, } \\
\text { insulin treatment and } \\
\text { cerebral metabolism }\end{array}$ & $\begin{array}{l}\text { There was no direct association between CMD-glucose levels } \\
\text { and the energy content of the administered enteral nutrition. } \\
\text { There was a significant association between CMD and serum } \\
\text { glucose levels. When the CMD-LPR was }<40 \text {, higher CMD } \\
\text { and serum glucose levels were associated with a higher } \\
\text { insulin dose. When the CMD-LPR was }>40 \text {, a higher insulin } \\
\text { dose was associated with lower CMD-glucose levels, despite } \\
\text { higher serum glucose concentrations }\end{array}$ \\
\hline (67) & $\begin{array}{l}\text { Single ceter, } \\
\text { prospective, } \\
\text { observational }\end{array}$ & 19 & $\begin{array}{l}\text { WFNS grade I } n=1 \\
(5.3 \%), \| n=1(5.3 \%) \\
\text { III } n=1(5.3 \%), I V \\
n=11(58 \%), V n=5 \\
(26 \%)\end{array}$ & $\begin{array}{l}\text { The mean monitoring } \\
\text { time was } 147 \mathrm{~h} \text {. Data } \\
\text { are reported for days } \\
1-7 \text { after SAH }\end{array}$ & $\begin{array}{l}\text { Cortical, frontal, classified } \\
\text { as radiologically normal- } \\
\text { appearing or adjacent to } \\
\text { ischemic lesions }\end{array}$ & $\begin{array}{l}\text { To elucidate the relation } \\
\text { between brain and serum } \\
\text { glucose levels }\end{array}$ & $\begin{array}{l}\text { CMD-glucose levels decreased over days } 1-7 \text {. There was } \\
\text { a significant correlation between CMD and serum glucose } \\
\text { levels }(r=0.27) \text {. CMD-lactate and CMD-pyruvate levels } \\
\text { increased over time, beginning on day 3. CMD-glutamate } \\
\text { levels peaked on day } 1 \text { and decreased thereafter. CMD- } \\
\text { glucose and CMD-pyruvate levels decrease during insulin } \\
\text { treatment, despite systemic glucose concentrations within } \\
\text { normal range }\end{array}$ \\
\hline
\end{tabular}

SAH, subarachnoid hemorrhage; CMD, cerebral microdialysis; LPR, lactate-to-pyruvate-ratio; GCS, Glasgow coma scale; WFNS, world federation of neurological societies. 
summary, tight glycemic control may be associated with pathologically low CMD-glucose levels (neuroglucopenia) in critically ill patients with acute neurologic injury. If brain metabolic monitoring indicates critically low glucose levels (i.e., $<0.2 \mathrm{mmol} / \mathrm{l}$ ) targeting a more liberal glucose regimen $(110-150 \mathrm{mg} / \mathrm{dl}$ or up to $180 \mathrm{mg} / \mathrm{dl}$ ) may be indicated.

\section{CMD and Outcome}

Studies reporting an association of CMD parameters with patient outcome are summarized in Table 7. The largest study includes 182 SAH patients and found higher CMD-LPR and CMD-glutamate values during the first week after SAH being significantly and independently associated with poor functional outcome after 12 months (50). Patients with poor functional 3-6 months outcome had significantly more episodes of CMDLPR > 40 and CMD-glutamate levels $>10 \mu \mathrm{mol} / \mathrm{l}$ compared to those with favorable outcome (71). An elevated CMD-LPR was also associated with hospital mortality (57). Pathologically low CMD-glucose levels $<0.7 \mathrm{mmol} / \mathrm{l}$ were observed more often in patients with poor outcome and in those who died (41, 61, 63). Elevated CMD-lactate is a less specific marker for neuroprognostication, as both, associations with good (in a hyperglycolytic context) and poor (due to hypoxia) outcome were reported (72).

Trend analysis is important as a shift to hypermetabolism, indicated by an increase in both, CMD-lactate and CMDpyruvate levels, was observed in patients with favorable outcome. Persistent low CMD-pyruvate levels without increase to normal values were associated with poor outcome (69). Persistent low CMD-glutamate levels were associated with good functional outcome, whereas increases at day 1 and day 7 were associated with poor outcome (74).

\section{DISCUSSION}

This review demonstrates that CMD is a powerful tool providing almost continuous brain metabolic information at bedside. Based on the published literature, pathological changes in brain metabolism are associated with disease severity, mechanisms of primary and secondary brain injury, and poor long-term outcome after SAH.

As summarized in this review, the major limitation of the published literature is that CMD monitoring was reported mostly in small single-center trials of neurological and neurosurgical ICUs with extensive experience in the use of CMD as adjunct to other multimodal neuromonitoring techniques. In many centers, implementation of CMD as a clinical tool is still limited due to financial constraints and the lack of evidence to improve patient's outcome. Future trials may address this gap in the literature by targeting brain metabolic parameters as endpoints to improve brain homeostasis as no monitoring tool can improve patient's outcome unless coupled with a therapeutic intervention. On the other hand, there is a need to re-define commonly used outcome parameters and to move from a simplistic functional outcome score to a more sophisticated approach including neuropsychological testing, quality of life measures, and brain tissue outcome.

The invasiveness of CMD limits its application to poor-grade $\mathrm{SAH}$ patients. This implicates that this review merely summarizes brain metabolic changes of unconscious patients and results are not generalizable to all clinical grades. Based on the recently published consensus statement, the use of CMD is recommended in poor-grade SAH patients with prolonged ventilation and patients with secondary neurologic deterioration requiring mechanical ventilation.

Despite these limitations metabolic monitoring in the early and subacute phase after SAH provides insight into pathophysiological mechanisms of primary and secondary brain injury on the brain tissue level. As shown in our review, the detection of impeding ischemia is the most extensively studied application of CMD in SAH patients. CMD has been shown to have the potential to be used as early warning tool of brain tissue ischemia hours before the insult $(17,43,44)$, even if clinically silent (26). In this regard, it is important to mention that we recognized a large variability in the definition of DCI throughout the published literature. Although more homogeneity was detected after the year 2010 when Vergouwen et al. defined DCI based on clinical and/or radiographic criteria (83), earlier studies are difficult to compare as information on radiographic evidence of new infarctions related to vasospasm were commonly not reported.

Another limitation is that microdialysis probe location differed in individual studies by means of targeting either brain tissue ipsilateral to the bleeding aneurysm or the contralateral hemisphere and monitoring the cortical gray matter vs. subcortical white matter. Furthermore, probe location was rarely adequately addressed as covariate in multivariate models, which limits the interpretation of results and conclusions. It is important to mention that brain chemistry can only be interpreted correctly based on the relation to focal injury on brain imaging ("normal appearing brain tissue" vs. "perilesional" vs. "intralesional”) (2). As recommended by clinical experts, future trials reporting microdialysis data should at least include information on catheter location, the catheter type used, perfusion fluid composition, the perfusion fluid flow rate, and time from ictus to monitoring (2).

The interpretation of $\mathrm{CMD}$-derived information requires profound knowledge of the complex underlying pathophysiology. As shown in Table 1, metabolic changes may be ambiguous, as similar patterns may indicate different underlying pathophysiological processes. However, taking into account, the occurrence of specific patterns in relation to the bleeding onset may help to discriminate between early and late onset ischemic patterns or patterns of mitochondrial dysfunction. A clinical guidance is given in Table $\mathbf{1}$ and may be combined with other neuromonitoring parameters such as brain tissue oxygenation, $\mathrm{ICP}$, and CBF.

Clinical implication of microdialysis monitoring besides the detection of secondary ischemic insults include guidance of systemic glucose management, CPP optimization, defining individual transfusion thresholds and monitoring of brain chemistry during pharmacological and non-pharmacological interventions $(41,49,51,52,57,61,63,67)$.

The only treatment decision based on changes in brain metabolism currently recommended by clinical experts is the treatment of low cerebral glucose taking into account baseline 
TABLE 7 | Brain metabolism and outcome after SAH.

\begin{tabular}{|c|c|c|c|c|c|c|c|}
\hline Reference & Study type & $\begin{array}{l}\text { Number of } \\
\text { patients with } \\
\text { SAH }\end{array}$ & $\begin{array}{l}\text { Patient } \\
\text { characteristics }\end{array}$ & Monitoring period & Probe location & Study aim & Main microdialysis findings \\
\hline (68) & $\begin{array}{l}\text { Single-center, } \\
\text { prospective, } \\
\text { observational }\end{array}$ & 28 & $\begin{array}{l}\text { Hunt and Hess grade } \\
\begin{array}{l}\| n=3(11 \%), \text { III } \\
n=6(21 \%), I V n=3 \\
(11 \%), \mathrm{V} n=16(57 \%)\end{array}\end{array}$ & $\begin{array}{l}\text { Monitoring was initiated } 1 \text { day } \\
\text { (median) after SAH. Data are } \\
\text { reported up to } 12 \text { days after } \\
\text { SAH }\end{array}$ & $\begin{array}{l}\text { White matter at greatest } \\
\text { risk for secondary brain } \\
\text { injury; classified as normal or } \\
\text { perilesional tissue }\end{array}$ & $\begin{array}{l}\text { Investigating associations } \\
\text { between } \mathrm{CMD}-\mathrm{K}^{+} \text {levels, } \\
\text { brain metabolism and } \\
\text { functional outcome }\end{array}$ & $\begin{array}{l}\text { Elevated cerebral CMD-K+ levels (above the } \\
\text { median of } 3 \mathrm{mmol} / \mathrm{I} \text { ) were associated with } \\
\mathrm{CMD}-\mathrm{LPR}>40, \mathrm{CMD} \text {-lactate }>4 \mathrm{mmol} / \mathrm{I} \\
\text { and poor outcome. CMD-K+ concentrations } \\
\text { positively correlated with CMD-lactate and } \\
\text { CMD-glutamate levels and the CMD- } \\
\text { LPR. CMD-LPR }>40 \text { was independently } \\
\text { associated with poor functional outcome }\end{array}$ \\
\hline (69) & $\begin{array}{l}\text { Single-center, } \\
\text { prospective, } \\
\text { observational }\end{array}$ & 20 & $\begin{array}{l}\text { Hunt and Hess grade } \\
\text { III } n=10, I V n=6 \\
\text { V } n=4\end{array}$ & $\begin{array}{l}\text { CMD monitoring started within } \\
24 \mathrm{~h} \text { after SAH in most patients } \\
\text { and was maintained for } \\
3-12 \text { days (range) }\end{array}$ & Cortical, frontal & $\begin{array}{l}\text { Describing metabolic profiles } \\
\text { in relation to functional } \\
\text { outcome }\end{array}$ & $\begin{array}{l}\text { A metabolic pattern of decreasing CMD- } \\
\text { glucose levels paralleled by an increase } \\
\text { in both, CMD-lactate and CMD-pyruvate } \\
\text { concentrations, after } 24-72 \mathrm{~h} \text { was common } \\
\text { in patients with good outcome. A pattern of } \\
\text { CMD-glucose levels remaining high combined } \\
\text { with low CMD-pyruvate concentrations was } \\
\text { common in patients with poor outcome }\end{array}$ \\
\hline (70) & $\begin{array}{l}\text { Single-center, } \\
\text { prospective, } \\
\text { randomized- } \\
\text { controlled }\end{array}$ & $30 / 60$ & $\begin{array}{l}\text { GCS score average } \\
\text { of } 5\end{array}$ & $\mathrm{n} / \mathrm{a}$ & $\mathrm{n} / \mathrm{a}$ & $\begin{array}{l}\text { Comparing an ICP-based } \\
\text { to a CPP-based treatment } \\
\text { concept }\end{array}$ & $\begin{array}{l}\text { Patients with poor outcome had significantly } \\
\text { lower levels of CMD-glucose ( } 1.1 \mathrm{vs} \text {. } \\
2.1 \mathrm{mmol} / \mathrm{l}) \text { and higher levels of CMD-glycerol } \\
\text { and a higher CMD-LPR compared to patients } \\
\text { with good outcome }\end{array}$ \\
\hline (14) & $\begin{array}{l}\text { Single-center, } \\
\text { prospective, } \\
\text { observational }\end{array}$ & 26 & $\begin{array}{l}\text { Hunt and Hess } \\
\text { grade II } n=2(7.7 \%) \\
\text { III } n=6(23.1 \%) \\
\mathrm{IV} n=2(7.7 \%), \mathrm{V} \\
n=16(61.5 \%)\end{array}$ & $\begin{array}{l}\text { Monitoring was started } 22 \mathrm{~h} \\
\text { (median) after SAH and data } \\
\text { of the following } 144 \mathrm{~h} \text { are } \\
\text { reported }\end{array}$ & $\begin{array}{l}\text { Frontal, ipsilateral to the } \\
\text { aneurysm; classified as normal- } \\
\text { appearing or perilesional brain } \\
\text { tissue }\end{array}$ & $\begin{array}{l}\text { Describing the metabolic } \\
\text { profile during the early phase } \\
\text { after SAH }\end{array}$ & $\begin{array}{l}\text { A higher CMD-LPR was associated with poor } \\
\text { outcome }\end{array}$ \\
\hline (15) & $\begin{array}{l}\text { Single-center, } \\
\text { prospective, } \\
\text { observational }\end{array}$ & 39 & $\begin{array}{l}\text { Hunt and Hess } \\
\text { grade I + II } n=3 \\
(8 \%), I I I n=6(15 \%), \\
\text { IV } n=12(31 \%), V \\
n=18(46 \%)\end{array}$ & $\begin{array}{l}\text { Data are reported for days } \\
2-10 \text { after SAH }\end{array}$ & $\begin{array}{l}\text { Frontal, contralateral to the } \\
\text { craniotomy in clipped patients; } \\
\text { non-dominant hemisphere } \\
\text { in diffuse SAH or ipsilateral } \\
\text { in lateralized SAH in coiled } \\
\text { patients }\end{array}$ & $\begin{array}{l}\text { Comparing brain metabolism } \\
\text { of patients with and without } \\
\text { global cerebral edema on } \\
\text { admission }\end{array}$ & $\begin{array}{l}\text { CMD-LPR > } 40 \text { and metabolic crisis (CMD- } \\
\text { LPR }>40 \text { and CMD-glucose }<0.7 \text { mmo//l) } \\
\text { were associated with poor outcome }\end{array}$ \\
\hline$(57)$ & $\begin{array}{l}\text { Single ceter, } \\
\text { prospective, } \\
\text { observational }\end{array}$ & 28 & $\begin{array}{l}\text { Hunt and Hess grade } \\
\text { III } n=6(21 \%), \text { IV } \\
n=8(29 \%), \mathrm{V} n=14 \\
(50 \%)\end{array}$ & $\begin{array}{l}\text { Monitoring was initiated on } \\
\text { day } 2 \text { (median) after SAH and } \\
\text { maintained for } 6 \text { days (median) }\end{array}$ & $\begin{array}{l}\text { White matter, frontal, tissue } \\
\text { at risk or contralateral to the } \\
\text { craniotomy }\end{array}$ & $\begin{array}{l}\text { To assess the relationship } \\
\text { between rapid reductions } \\
\text { in serum glucose and brain } \\
\text { metabolism }\end{array}$ & $\begin{array}{l}\text { A higher CMD-LPR was associated with } \\
\text { hospital mortality }\end{array}$ \\
\hline$(71)$ & $\begin{array}{l}\text { Single-center, } \\
\text { prospective, } \\
\text { observational }\end{array}$ & $35 / 40$ & $\begin{array}{l}\text { Admission WFNS } \\
\text { grade } \mathrm{IV}+\mathrm{V} n=22\end{array}$ & $\begin{array}{l}\text { Data are reported for days } \\
2-17 \text { after } \mathrm{SAH} \text {. The mean } \\
\text { monitoring time per patient } \\
\text { was } 4 \text { days }\end{array}$ & $\begin{array}{l}\text { Frontal or suspected } \\
\text { aneurysmal vascular territory }\end{array}$ & $\begin{array}{l}\text { Investigating the association } \\
\text { between brain metabolism } \\
\text { and patient outcome }\end{array}$ & $\begin{array}{l}\text { Patients with unfavorable outcome showed } \\
\text { a higher CMD-LPR compared to those with } \\
\text { good outcome. Episodes of CMD-LPR }>40 \\
\text { or CMD-glutamate levels }>10 \mu \mathrm{mol} / \mathrm{l} \text { were } \\
\text { both associated with cerebral infarction and } \\
\text { poor outcome }\end{array}$ \\
\hline
\end{tabular}


TABLE 7 | Continued

Reference Study type

Number of Patient

Monitoring period

Probe location

Study aim

Main microdialysis findings

SAH

(50)

Single-center,
prospective,

182

Monitoring was started

WFNS grade $0 n=3$

Vascular territory of the

$(2 \%), \ln =61(37 \%)$

$13 \mathrm{~h}$ (mean) after SAH

aneurysm; insertion into

observational

$n=17(10 \%)$, IV

and maintained for 169/172 $\mathrm{h}$

aneurysm; insertion into

Investigating the impact of

Higher CMD-LPR and CMD-glutamate levels

$n=35(21 \%), V \quad$ intracranial hypertension

$n=25$ (15\%)

(61) Single ceter, observational

$10 / 20$

GCS score 7

(median), 3-10

CMD monitoring was started

(range)
$45 \mathrm{~h}$ (median) after SAH and
Frontal, near the area of

lesioned tissue or right frontal

injury
Investigating the impact of Blood glucose levels were defined as

tight glycemic control on "tight" (4.4-6.7 mmol/l) or "intermediate"

(6. 8-10 mmo///). Tight blood glucose was

associated with lower levels of CMD-glucose,

more episodes of CMD-glucose $<0.7 \mathrm{mmo} / \mathrm{l}$, higher CMD-LPR and a more frequent

occurrence of metabolic crisis (CMD-LPR $>40$ and CMD-glucose levels $<0.7 \mathrm{mmol} / \mathrm{l})$. Low

CMD-glucose levels and metabolic crisis were associated with higher hospital mortality

(51) Single-center, prospective,

observational

Hunt and Hess grade Monitoring was initiated 1 day II $n=2$, III $n=4$, IV (median) after SAH. Between 37 and 168 hourly samples

White matter, contralatera to the maximal focal injury normal-appearing tissue

To assess the impact of nduced normothermia on cerebral metabolism

When normothermia $\left(37^{\circ} \mathrm{C}\right)$ was induced

due to refractory fever $\left(\geq 38.3^{\circ} \mathrm{C}\right)$, it was associated with a decrease in CMD-LPR and fewer episodes of metabolic distress (CMD-

LPR > 40). Patients with poor outcome had a higher CMD-LPR

(72) Two-center

$31 \quad$ Comatose patients

Monitoring was started 1

Visually normal white matter

prospective,

day (median) after SAH and

maintained for 7 days (median)

To elucidate the relevance of elevated CMD-lactate levels in the context of brain tissue hypoxia and hyperglycolysis

-lactate concentrations ( $>4 \mathrm{mmol} / \mathrm{l}$ ) were defined as "hypoxic" (together with $\mathrm{Pbt}_{\mathrm{bi}} \mathrm{O}_{2}<20 \mathrm{mmHg}$ )

"hyperglycolytic" (together with CMDpyruvate concentrations $>119 \mu \mathrm{mol} / \mathrm{l})$, or neither. Hyperglycolytic elevated CMD-lactate was more common than hypoxic elevated CMD-lactate and associated with favorable outcome. Hypoxic elevated CMD-lactate was associated with an increased mortality

\begin{tabular}{|c|c|c|c|c|c|c|}
\hline $\begin{array}{l}\text { (73) } \\
\text { (abstract } \\
\text { only) }\end{array}$ & $\begin{array}{l}\text { Single-center, } \\
\text { prospective, } \\
\text { observational }\end{array}$ & $18 / 51$ & $\mathrm{n} / \mathrm{a}$ & $\mathrm{n} / \mathrm{a}$ & $\mathrm{n} / \mathrm{a}$ & $\begin{array}{l}\text { To correlate CMD findings } \\
\text { with functional outcome }\end{array}$ \\
\hline (33) & $\begin{array}{l}\text { Single-center, } \\
\text { prospective } \\
\text { observational }\end{array}$ & 10 & $\begin{array}{l}\text { Hunt and Hess grade } \\
\begin{array}{l}\| n=3(30 \%), \text { III } \\
n=4(40 \%), \text { IV } n=3 \\
(30 \%)\end{array}\end{array}$ & $\begin{array}{l}\text { Start time is not exactly given } \\
\text { (figures indicate } 12-30 \mathrm{~h} \\
\text { after } \mathrm{SAH}) . \text { Monitoring lasted } \\
6-11 \text { days (range) }\end{array}$ & Cortical, frontal & $\begin{array}{l}\text { To match CMD data with CT } \\
\text { findings, clinical course and } \\
\text { outcome }\end{array}$ \\
\hline
\end{tabular}

Poor 12-month outcome was correlated with ower CMD-glucose levels and higher levels of CMD-glycerol and CMD-LPR

$\mathrm{MD}$-lactate elevations were frequently

observed without obvious cause, while CMD

LPR reflected ischemia and, during days $0-4$, correlated with outcome. In an infracted area, CMD-glucose levels fell to and remained at 0 . Zero-levels of CMD-glucose were observed more frequently in patients with poor outcome. Patients with poor outcome had significantly higher CMD-glutamate levels 
TABLE 7 | Continued

\begin{tabular}{|c|c|c|c|c|c|c|c|}
\hline Reference & Study type & $\begin{array}{c}\text { Number of } \\
\text { patients with } \\
\text { SAH }\end{array}$ & $\begin{array}{l}\text { Patient } \\
\text { characteristics }\end{array}$ & Monitoring period & Probe location & Study aim & Main microdialysis findings \\
\hline (18) & $\begin{array}{l}\text { Single-center, } \\
\text { prospective, } \\
\text { observational }\end{array}$ & 149 & $\begin{array}{l}\text { WFNS grade } 0 n=3 \\
\begin{array}{l}(2 \%), I n=53(36 \%), \\
\| n=16(11 \%), \text { III } \\
n=17(11 \%), I V \\
n=33(22 \%), \text { V } \\
n=27(18 \%)\end{array}\end{array}$ & $\begin{array}{l}\text { Monitoring was started } \\
\text { after aneurysm treatment } \\
\text { (mean } 24.7 \mathrm{~h} \text { after SAH) and } \\
\text { maintained for } 161.8 \mathrm{~h} \text { (mean) }\end{array}$ & $\begin{array}{l}\text { Vascular territory of the } \\
\text { aneurysm; insertion into } \\
\text { lesioned tissue was avoided }\end{array}$ & $\begin{array}{l}\text { Investigating the relationship } \\
\text { between clinical disease } \\
\text { severity, brain metabolism } \\
\text { and outcome }\end{array}$ & $\begin{array}{l}\text { Higher CMD-glutamate levels and CMD-LPR } \\
\text { were independently associated with poor } \\
\text { functional outcome and mortality }\end{array}$ \\
\hline (20) & $\begin{array}{l}\text { Single-center, } \\
\text { prospective, } \\
\text { observational }\end{array}$ & 26 & $\begin{array}{l}\text { Hunt and Hess grade } \\
\text { II } n=1(4 \%), \text { III } n=7 \\
(26 \%), I V n=2(8 \%) \\
\text { V } n=16(62 \%)\end{array}$ & $\begin{array}{l}\text { Monitoring was started } 1 \text { day } \\
\text { (median) after SAH and } \\
\text { maintained for } 4 \text { days (median) }\end{array}$ & $\begin{array}{l}\text { Vascular territory of the } \\
\text { aneurysm; classified as normal- } \\
\text { appearing or perilesional brain } \\
\text { tissue }\end{array}$ & $\begin{array}{l}\text { To investigate the association } \\
\text { between neuroinflammation, } \\
\text { axonal injury and brain } \\
\text { metabolism }\end{array}$ & $\begin{array}{l}\text { High-grade neuroinflammation (CMD-IL-6 } \\
\text { levels above median) was associated with } \\
\text { poor functional outcome }\end{array}$ \\
\hline (63) & $\begin{array}{l}\text { Single ceter, } \\
\text { prospective, } \\
\text { observational }\end{array}$ & 28 & $\begin{array}{l}\text { WFNS grade I } n=8 \\
(29 \%), \| I n=6(21 \%) \\
I I I n=3(11 \%), \text { IV } \\
n=6(21 \%), V n=5 \\
(18 \%)\end{array}$ & $\begin{array}{l}\text { Monitoring was initiated } \\
22.2 \mathrm{~h} \text { (mean) after SAH and } \\
\text { maintained for } 195.4 \mathrm{~h} \text { (mean) }\end{array}$ & $\begin{array}{l}\text { Vascular territory of the } \\
\text { aneurysm; insertion into } \\
\text { lesioned tissue was avoided }\end{array}$ & $\begin{array}{l}\text { To investigate the impact of } \\
\text { hyperglycemia on cerebral } \\
\text { metabolism }\end{array}$ & $\begin{array}{l}\text { Low CMD-glucose levels during episodes of } \\
\text { blood glucose concentrations }>140 \mathrm{mg} / \mathrm{dl} \\
\text { was associated with poor outcome }\end{array}$ \\
\hline$(41)$ & $\begin{array}{l}\text { Single-center, } \\
\text { prospective, } \\
\text { observational }\end{array}$ & 30 & $\begin{array}{l}\text { Hunt and Hess grade } \\
\begin{array}{l}\|+\mathrm{II} n=5(17 \%) \\
\mathrm{IV} n=10(33 \%), \mathrm{V} \\
n=15(50 \%)\end{array}\end{array}$ & $\begin{array}{l}\text { Monitoring was started } 3 \text { days } \\
\text { (median) after } \mathrm{SAH} \text { and } \\
\text { maintained for } 110 \mathrm{~h} \text { (median) }\end{array}$ & $\begin{array}{l}\text { Frontal, ipsilateral to lateralized } \\
\text { aneurysms, right frontal lobe in } \\
\text { case of midline aneurysms }\end{array}$ & $\begin{array}{l}\text { To identify the relation } \\
\text { between CPP thresholds and } \\
\text { brain metabolic crisis }\end{array}$ & $\begin{array}{l}\text { Metabolic crisis (CMD-LPR > } 40 \text { and CMD- } \\
\text { glucose concentrations } \leq 0.7 \mathrm{mmol} / \mathrm{l} \text { ) was } \\
\text { associated with poor outcome }\end{array}$ \\
\hline (74) & $\begin{array}{l}\text { Single-center, } \\
\text { prospective, } \\
\text { observational }\end{array}$ & 10 & $\begin{array}{l}\text { Hunt and Hess grade } \\
\text { In=2, II } n=3, \text { III } \\
n=1, I V n=2, \mathrm{~V} \\
n=2\end{array}$ & $\begin{array}{l}\text { CMD was performed for } \\
1.7-7 \text { days (range). Data are } \\
\text { reported up to } 9 \text { days after } \\
\text { SAH }\end{array}$ & Frontal & $\begin{array}{l}\text { Investigating associations } \\
\text { between cerebral } \\
\text { metabolism and patient } \\
\text { outcome }\end{array}$ & $\begin{array}{l}\text { Higher concentrations of CMD-glutamate } \\
\text { and CMD-lactate were associated with } \\
\text { poor functional outcome. In patients with } \\
\text { poor outcome, glutamate levels followed a } \\
\text { biphasic course with peaks on days } 1-2 \text { and } \\
\text { 7. In patients with good outcome, glutamate } \\
\text { levels remained low without any temporal } \\
\text { dynamic }\end{array}$ \\
\hline (75) & $\begin{array}{l}\text { Single-center, } \\
\text { prospective, } \\
\text { observational }\end{array}$ & 18 & $\begin{array}{l}\text { WFNS grade IV } n=4 \\
(22 \%), \text { V } n=14(78 \%)\end{array}$ & $\begin{array}{l}\text { The median monitoring time } \\
\text { was } 8 \text { days }\end{array}$ & $\begin{array}{l}\text { Cortical, vascular territory of } \\
\text { the aneurysm }\end{array}$ & $\begin{array}{l}\text { Comparing CMD values to } \\
\text { the arterio-jugular difference }\end{array}$ & $\begin{array}{l}\text { No significant differences in absolute values } \\
\text { of CMD parameters were observed between } \\
\text { patients with good and poor outcome. CMD- } \\
\text { lactate levels }>4 \mathrm{mmol} / \mathrm{l} \text { and CMD-pyruvate } \\
\text { levels }>119 \mu \mathrm{mol} / / \text { were significantly more } \\
\text { common in patients with good outcome. } \\
\text { Hypoxic elevated lactate }\left(\mathrm{P}_{\mathrm{bt}} \mathrm{O}_{2}<20 \mathrm{mmHg}\right) \\
\text { was more common in patients with poor } \\
\text { outcome }\end{array}$ \\
\hline
\end{tabular}

SAH, subarachnoid hemorrhage; CMD, cerebral microdialysis; $L P R$, lactate-to-pyruvate-ratio; GCS, Glasgow coma scale; $n / a$, data not available; ICP, intracranial pressure; $C P P$, cerebral perfusion pressure; $P_{b i} O_{2}$, brain tissue oxygen tension; CBF, cerebral blood flow; IL-6, interleukin-6. 
TABLE 8 | CMD findings not directly related to the discussed topics.

\begin{tabular}{|c|c|c|c|c|c|c|c|}
\hline Reference & Study type & $\begin{array}{l}\text { Number of } \\
\text { patients with } \\
\text { SAH }\end{array}$ & Patient characteristics & Monitoring period & Probe location & Study aim & Main microdialysis findings \\
\hline $\begin{array}{l}\text { (76) (abstract } \\
\text { only) }\end{array}$ & $\mathrm{n} / \mathrm{a}$ & $\mathrm{n} / \mathrm{a}$ & $n / a$ & $\begin{array}{l}\text { Data are reported } \\
\text { between } 2 \text { and } 12 \text { days } \\
\text { after SAH }\end{array}$ & $\mathrm{n} / \mathrm{a}$ & $\begin{array}{l}\text { Investigating the effect } \\
\text { of remote ischemic } \\
\text { preconditioning on brain } \\
\text { metabolism }\end{array}$ & $\begin{array}{l}\text { Over the duration of remote ischemic } \\
\text { preconditioning, the CMD-LPR and CMD- } \\
\text { glycerol levels decreased. The effect persisted } \\
\text { for } 25-54 \mathrm{~h}\end{array}$ \\
\hline (77) & $\begin{array}{l}\text { Single-center, } \\
\text { prospective, } \\
\text { observational }\end{array}$ & 5 & $\begin{array}{l}\text { WFNS grade } I n=5 \\
(100 \%)\end{array}$ & $\begin{array}{l}\text { All patients were operated } \\
\text { within } 1-3 \text { days after SAH }\end{array}$ & $\begin{array}{l}\text { Frontal or temporal, } \\
\text { vascular territory most } \\
\text { likely affected by } \\
\text { vasospasm }\end{array}$ & $\begin{array}{l}\text { Describing CMD levels in } \\
\text { good-grade SAH patients }\end{array}$ & $\begin{array}{l}\text { Mean levels of CMD parameters in WFNS grade } \\
\text { I patients were: CMD-glucose } 2.6 \mathrm{mmol} / / \text {, } \\
\text { CMD-lactate } 2.9 \mathrm{mmol} / \mathrm{l}, \mathrm{CMD} \text {-pyruvate } \\
92 \mu \mathrm{mo} / / \mathrm{l}, \mathrm{CMD} \text {-LPR } 36, \text { CMD-glutamate } \\
11.2 \mu \mathrm{mo} / / \mathrm{l}\end{array}$ \\
\hline (78) & $\begin{array}{l}\text { Single-center, } \\
\text { prospective, } \\
\text { observational }\end{array}$ & 17 & $\begin{array}{l}\text { WFNS grade I } n=1, \| \\
n=3, \| I n=5, I V n=3 \\
\vee n=5\end{array}$ & $\begin{array}{l}\text { Probes were inserted } \\
\text { within } 72 \mathrm{~h} \text { after SAH. } \\
\text { Monitoring was performed } \\
\text { for } 85-336 \mathrm{~h} \text { (range) }\end{array}$ & $\begin{array}{l}\text { Vascular territory of the } \\
\text { aneurysm; insertion } \\
\text { into lesioned tissue was } \\
\text { avoided }\end{array}$ & $\begin{array}{l}\text { Investigating the association } \\
\text { between CSD and brain } \\
\text { metabolism }\end{array}$ & $\begin{array}{l}\text { Patients with acute focal neurological deficits } \\
\text { had higher baseline CMD-glutamate and } \\
\text { CMD-lactate levels compared to those without. } \\
\text { In patients without acute focal deficits, there } \\
\text { was a significant transient decrease in CMD- } \\
\text { glucose }(-25 \%) \text { and increase in CMD-lactate } \\
\text { concentrations (+10\%) following clusters of } \\
\text { CSDs ( } 2 \text { or more per hour), but not single } \\
\text { CSDs. No changes in CMD-glutamate levels } \\
\text { were observed }\end{array}$ \\
\hline $\begin{array}{l}\text { (79) (abstract } \\
\text { only) }\end{array}$ & $\begin{array}{l}\text { Bi-center, } \\
\text { prospective, } \\
\text { observational }\end{array}$ & 21 & $\begin{array}{l}\text { WFNS grade }|-| I \mid n=11 \\
I V-V n=10\end{array}$ & $\begin{array}{l}\text { Data are reported up to } \\
14 \text { days after SAH }\end{array}$ & $\begin{array}{l}\text { Vascular territory at risk } \\
\text { for DCl }\end{array}$ & $\begin{array}{l}\text { To investigate an association } \\
\text { between CSD and CMD- } \\
\text { glucose level }\end{array}$ & $\begin{array}{l}\text { CSD were not associated with changes in } \\
\text { CMD-glucose levels }\end{array}$ \\
\hline (80) & $\begin{array}{l}\text { Single-center, } \\
\text { retrospective, } \\
\text { observational }\end{array}$ & 167 & $\begin{array}{l}\text { WFNS grade } 0 n=3 \\
(2 \%), I n=58(35 \%), \| \\
n=21(13 \%), I I I n=18 \\
(11 \%), \text { IV } n=38(23 \%), V \\
n=29(17 \%)\end{array}$ & $\begin{array}{l}\text { Data are reported for } \\
\text { days } 1-10 \text { after } \mathrm{SAH} \text {. } \\
\text { CMD was performed for } \\
7-10 \text { days }\end{array}$ & $\begin{array}{l}\text { Vascular territory of the } \\
\text { aneurysm; patients were } \\
\text { excluded if the tip of the } \\
\text { CMD probe was close to a } \\
\text { parenchymal hemorrhage }\end{array}$ & $\begin{array}{l}\text { To relate changes in cerebral } \\
\text { metabolism to the emergence } \\
\text { of bacterial meningitis }\end{array}$ & $\begin{array}{l}\text { On the day when bacterial meningitis was } \\
\text { diagnosed, CMD-glucose levels and the CMD- } \\
\text { lactate-to-glucose-ratio were significantly lower } \\
\text { than } 3 \text { days before. Compared to controls, } \\
\text { only the decrease in CMD-glucose levels was } \\
\text { more pronounced in patients with bacterial } \\
\text { meningitis. A decrease in CMD-glucose levels } \\
\text { of } 1 \mathrm{mmol} / \mathrm{l} \text { showed the highest combined } \\
\text { sensitivity and specificity }\end{array}$ \\
\hline $\begin{array}{l}\text { (81) (Abstract } \\
\text { only) }\end{array}$ & $\begin{array}{l}\text { Single-center, } \\
\text { prospective, } \\
\text { observational }\end{array}$ & 4 & $\mathrm{n} / \mathrm{a}$ & $\mathrm{n} / \mathrm{a}$ & $\mathrm{n} / \mathrm{a}$ & $\begin{array}{l}\text { Investigating the impact of } \\
\text { temperature changes on } \\
\text { CMD-glutamate levels }\end{array}$ & $\begin{array}{l}\text { In all patients, mild head cooling resulted in a } \\
\text { significant decrease in CMD-glutamate levels. } \\
\text { In } 2 \text { patients, CMD-glutamate concentrations } \\
\text { increased sharply with fever }\end{array}$ \\
\hline (82) & $\begin{array}{l}\text { Single-center, } \\
\text { prospective, } \\
\text { observational }\end{array}$ & $6 / 18$ & $\begin{array}{l}\text { GCS motor score } 3 \\
n=3,5 n=1,6 n=2\end{array}$ & $\mathrm{n} / \mathrm{a}$ & $\begin{array}{l}\text { Cortical, normal-appearing } \\
\text { tissue }\end{array}$ & $\begin{array}{l}\text { To assess the impact of fever } \\
\text { on cerebral metabolism }\end{array}$ & $\begin{array}{l}\text { Neither the onset of fever }\left(\geq 38.7^{\circ} \mathrm{C}\right) \text { nor its } \\
\text { resolution was associated with significant } \\
\text { changes in cerebral metabolism }\end{array}$ \\
\hline
\end{tabular}

n/a, data not available; SAH, subarachnoid hemorrhage; CMD, cerebral microdialysis; LPR, lactate-to-pyruvate-ratio; WFNS, world federation of neurological societies; CSD, cortical spreading depolarizations; DCI, delayed cerebral ischemia. 
systemic glucose concentration, catheter location, and the etiology of neuroglucopenia. In the knowledge of its potential, there is a need to integrate brain metabolic changes and to define CMDbased endpoints in future clinical trials.

\section{CONCLUSION}

Cerebral microdialysis is used in the clinical management of severe $\mathrm{SAH}$ together with ICP, $\mathrm{P}_{\mathrm{bt}} \mathrm{O}_{2}$, and other neuromonitoring parameters. In the knowledge of its limitations, this method provides a novel insight into pathophysiological processes of primary and secondary brain injury. Recent consensus on microdialysis monitoring paves the way for improved protocols and targeted interventions. The major task for future research integrates the prospective evaluation of predefined interventions to improve

\section{REFERENCES}

1. Persson L, Hillered L. Chemical monitoring of neurosurgical intensive care patients using intracerebral microdialysis. J Neurosurg (1992) 76(1):72-80. doi:10.3171/jns.1992.76.1.0072

2. Hutchinson PJ, Jalloh I, Helmy A, Carpenter KL, Rostami E, Bellander BM, et al. Consensus statement from the 2014 International Microdialysis Forum. Intensive Care Med (2015) 41(9):1517-28. doi:10.1007/s00134-015-3930-y

3. Ungerstedt U. Microdialysis - principles and applications for studies in animals and man. J Intern Med (1991) 230(4):365-73. doi:10.1111/j.1365-2796.1991. tb00459.x

4. Hutchinson PJ, O'Connell MT, Nortje J, Smith P, Al-Rawi PG, Gupta AK, et al. Cerebral microdialysis methodology - evaluation of $20 \mathrm{kDa}$ and $100 \mathrm{kDa}$ catheters. Physiol Meas (2005) 26(4):423-8. doi:10.1088/0967-3334/26/4/008

5. Hutchinson PJ, O'Connell MT, Al-Rawi PG, Maskell LB, Kett-White R, Gupta AK, et al. Clinical cerebral microdialysis: a methodological study. J Neurosurg (2000) 93(1):37-43. doi:10.3171/jns.2000.93.1.0037

6. Bellander BM, Cantais E, Enblad P, Hutchinson P, Nordstrom CH, Robertson C, et al. Consensus meeting on microdialysis in neurointensive care. Intensive Care Med (2004) 30(12):2166-9. doi:10.1007/s00134-004-2461-8

7. Sehba FA, Pluta RM, Zhang JH. Metamorphosis of subarachnoid hemorrhage research: from delayed vasospasm to early brain injury. Mol Neurobiol (2011) 43(1):27-40. doi:10.1007/s12035-010-8155-Z

8. Starke RM, Connolly ES Jr; Participants in the International Multi-Disciplinary Consensus Conference on the Critical Care Management of Subarachnoid, Hemorrhage. Rebleeding after aneurysmal subarachnoid hemorrhage. Neurocrit Care (2011) 15(2):241-6. doi:10.1007/s12028-011-9581-0

9. Hutchinson PJ, Al-Rawi PG, O'Connell MT, Gupta AK, Maskell LB, Hutchinson DB, et al. Monitoring of brain metabolism during aneurysm surgery using microdialysis and brain multiparameter sensors. Neurol Res (1999) 21(4):352-8. doi:10.1080/01616412.1999.11740943

10. Hutchinson PJ, O'Connell MT, Al-Rawi PG, Kett-White CR, Gupta AK, Maskell LB, et al. Increases in GABA concentrations during cerebral ischaemia: a microdialysis study of extracellular amino acids. J Neurol Neurosurg Psychiatry (2002) 72(1):99-105. doi:10.1136/jnnp.72.1.99

11. Kett-White R, Hutchinson PJ, Al-Rawi PG, Czosnyka M, Gupta AK, Pickard JD, et al. Cerebral oxygen and microdialysis monitoring during aneurysm surgery: effects of blood pressure, cerebrospinal fluid drainage, and temporary clipping on infarction. J Neurosurg (2002) 96(6):1013-9. doi:10.3171/jns.2002.96.6.1013

12. Kett-White R, Hutchinson PJ, al-Rawi PG, Gupta AK, O'Connell MT, Pickard JD, et al. Extracellular lactate/pyruvate and glutamate changes in patients during per-operative episodes of cerebral ischaemia. Acta Neurochir Suppl (2002) 81:363-5.

13. Bhatia R, Hashemi P, Razzaq A, Parkin MC, Hopwood SE, Boutelle MG, et al. Application of rapid-sampling, online microdialysis to the monitoring of brain metabolism during aneurysm surgery. Neurosurgery brain tissue physiology aiming toward a personalized management of SAH patients in the future.

\section{AUTHOR CONTRIBUTIONS}

RH was involved in the idea, design, data acquisition, article selection, writing, interpretation of data, and final revision of the manuscript. MK was involved in article selection, writing, interpretation of data, and final revision of the manuscript. AS, $M G$, and VR were involved in the data acquisition, interpretation of data, and final revision of the manuscript. BP, RB, and ES were involved in article selection, writing, interpretation of data, and final revision of the manuscript. All authors read and approved the final version of the manuscript and are accountable for the content, data interpretation, and data accuracy.

(2006) 58(4 Suppl 2):ONS-313-20; discussion ONS-321. doi:10.1227/01. NEU.0000208963.42378.83

14. Helbok R, Schiefecker AJ, Beer R, Dietmann A, Antunes AP, Sohm F, et al. Early brain injury after aneurysmal subarachnoid hemorrhage: a multimodal neuromonitoring study. Crit Care (2015) 19:75. doi:10.1186/s13054-0150809-9

15. Helbok R, Ko SB, Schmidt JM, Kurtz P, Fernandez L, Choi HA, et al. Global cerebral edema and brain metabolism after subarachnoid hemorrhage. Stroke (2011) 42(6):1534-9. doi:10.1161/STROKEAHA.110.604488

16. Sarrafzadeh A, Haux D, Sakowitz O, Benndorf G, Herzog H, Kuechler I, et al. Acute focal neurological deficits in aneurysmal subarachnoid hemorrhage: relation of clinical course, CT findings, and metabolite abnormalities monitored with bedside microdialysis. Stroke (2003) 34(6):1382-8. doi:10.1161/01. STR.0000074036.97859.02

17. Sarrafzadeh AS, Sakowitz OW, Kiening KL, Benndorf G, Lanksch WR, Unterberg AW. Bedside microdialysis: a tool to monitor cerebral metabolism in subarachnoid hemorrhage patients? Crit Care Med (2002) 30(5):1062-70. doi:10.1097/00003246-200205000-00018

18. Sarrafzadeh A, Haux D, Kuchler I, Lanksch WR, Unterberg AW. Poor-grade aneurysmal subarachnoid hemorrhage: relationship of cerebral metabolism to outcome. J Neurosurg (2004) 100(3):400-6. doi:10.3171/jns.2004. 100.3.0400

19. Sarrafzadeh AS, Thomale UW, Haux D, Unterberg AW. Cerebral metabolism and intracranial hypertension in high grade aneurysmal subarachnoid haemorrhage patients. Acta Neurochir Suppl (2005) 95:89-92. doi:10.1007/ 3-211-32318-X_19

20. Schiefecker AJ, Dietmann A, Beer R, Pfausler B, Lackner P, Kofler M, et al. Neuroinflammation is associated with brain extracellular TAU-protein release after spontaneous subarachnoid hemorrhage. Curr Drug Targets (2017) 18(12):1408-16. doi:10.2174/1389450117666160201111804

21. Zetterling M, Hallberg L, Hillered L, Karlsson T, Enblad P, Ronne Engstrom E. Brain energy metabolism in patients with spontaneous subarachnoid hemorrhage and global cerebral edema. Neurosurgery (2010) 66(6):1102-10. doi:10.1227/01.NEU.0000370893.04586.73

22. Zetterling M, Hillered L, Samuelsson C, Karlsson T, Enblad P, RonneEngstrom E. Temporal patterns of interstitial pyruvate and amino acids after subarachnoid haemorrhage are related to the level of consciousness - a clinical microdialysis study. Acta Neurochir (Wien) (2009) 151(7):771-80; discussion 780. doi:10.1007/s00701-009-0384-4

23. Chen HI, Stiefel MF, Oddo M, Milby AH, Maloney-Wilensky E, Frangos S, et al. Detection of cerebral compromise with multimodality monitoring in patients with subarachnoid hemorrhage. Neurosurgery (2011) 69(1):53-63; discussion 63. doi:10.1227/NEU.0b013e3182191451

24. De Micheli E, Pinna G, Piovan E, Prisco R, Hillered L, Persson L, et al. Monitoring subtle neurometabolic changes in subarachnoid hemorrhage patients using microdialysis: a study on 16 cases. Acta Neurochir Suppl (2001) 77:149-53. 
25. EnbladP, Valtysson J, Andersson J, Lilja A, ValindS, AntoniG, etal.Simultaneous intracerebral microdialysis and positron emission tomography in the detection of ischemia in patients with subarachnoid hemorrhage. J Cereb Blood Flow Metab (1996) 16(4):637-44. doi:10.1097/00004647-199607000-00014

26. Helbok R, Madineni RC, Schmidt MJ, Kurtz P, Fernandez L, Ko SB, et al. Intracerebral monitoring of silent infarcts after subarachnoid hemorrhage. Neurocrit Care (2011) 14(2):162-7. doi:10.1007/s12028-010-9472-9

27. Hillered L, Valtysson J, Enblad P, Persson L. Interstitial glycerol as a marker for membrane phospholipid degradation in the acutely injured human brain. J Neurol Neurosurg Psychiatry (1998) 64(4):486-91. doi:10.1136/jnnp. 64.4 .486

28. Jacobsen A, Nielsen TH, Nilsson O, Schalen W, Nordstrom CH. Bedside diagnosis of mitochondrial dysfunction in aneurysmal subarachnoid hemorrhage. Acta Neurol Scand (2014) 130(3):156-63. doi:10.1111/ane.12258

29. Kerner A, Schlenk F, Sakowitz O, Haux D, Sarrafzadeh A. Impact of hyperglycemia on neurological deficits and extracellular glucose levels in aneurysmal subarachnoid hemorrhage patients. Neurol Res (2007) 29(7):647-53. doi:10.1 179/016164107X248983

30. Nilsson OG, Brandt L, Ungerstedt U, Saveland H. Bedside detection of brain ischemia using intracerebral microdialysis: subarachnoid hemorrhage and delayed ischemic deterioration. Neurosurgery (1999) 45(5):1176-84; discussion 1184-5. doi:10.1097/00006123-199911000-00032

31. Papadopoulos D, Filippidis A, Krommidas G, Vretzakis G, Paterakis K, Komnos A, et al. Regional cerebral blood flow and cellular environment in subarachnoid hemorrhage: a thermal Doppler flowmetry and microdialysis study. Neurol Neurochir Pol (2017) 51(1):66-71. doi:10.1016/j.pjnns.2016.11.002

32. Patet C, Quintard H, Zerlauth JB, Maibach T, Carteron L, Suys T, et al. Bedside cerebral microdialysis monitoring of delayed cerebral hypoperfusion in comatose patients with poor grade aneurysmal subarachnoid haemorrhage. J Neurol Neurosurg Psychiatry (2017) 88(4):332-8. doi:10.1136/jnnp-2016313766

33. Persson L, Valtysson J, Enblad P, Warme PE, Cesarini K, Lewen A, et al. Neurochemical monitoring using intracerebral microdialysis in patients with subarachnoid hemorrhage. J Neurosurg (1996) 84(4):606-16. doi:10.3171/ jns.1996.84.4.0606

34. Radolf S, Smoll N, Drenckhahn C, Dreier JP, Vajkoczy P, Sarrafzadeh AS. Cerebral lactate correlates with early onset pneumonia after aneurysmal SAH. Transl Stroke Res (2014) 5(2):278-85. doi:10.1007/s12975-013-0292-Z

35. Rostami E, Engquist H, Johnson U, Howells T, Ronne-Engstrom E, Nilsson P, et al. Monitoring of cerebral blood flow and metabolism bedside in patients with subarachnoid hemorrhage - a Xenon-CT and Microdialysis Study. Front Neurol (2014) 5:89. doi:10.3389/fneur.2014.00089

36. Sakowitz OW, Sarrafzadeh AS, Benndorf G, Lanksch WR, Unterberg AW. On-line microdialysis following aneurysmal subarachnoid hemorrhage. Acta Neurochir Suppl (2001) 77:141-4.

37. Samuelsson C, Hillered L, Enblad P, Ronne-Engstrom E. Microdialysis patterns in subarachnoid hemorrhage patients with focus on ischemic events and brain interstitial glutamine levels. Acta Neurochir (Wien) (2009) 151(5):437-46; discussion 446. doi:10.1007/s00701-009-0265-x

38. Sarrafzadeh AS, Nagel A, Czabanka M, Denecke T, Vajkoczy P, Plotkin M. Imaging of hypoxic-ischemic penumbra with (18)F-fluoromisonidazole PET/ CT and measurement of related cerebral metabolism in aneurysmal subarachnoid hemorrhage. J Cereb Blood Flow Metab (2010) 30(1):36-45. doi:10.1038/ jcbfm.2009.199

39. Sarrafzadeh A, Haux D, Plotkin M, Ludemann L, Amthauer H, Unterberg A. Bedside microdialysis reflects dysfunction of cerebral energy metabolism in patients with aneurysmal subarachnoid hemorrhage as confirmed by $15 \mathrm{O}-\mathrm{H} 2$ O-PET and 18 F-FDG-PET. J Neuroradiol (2005) 32(5):348-51. doi:10.1016/ S0150-9861(05)83168-2

40. Sarrafzadeh AS, Haux D, Ludemann L, Amthauer H, Plotkin M, Kuchler I, et al. Cerebral ischemia in aneurysmal subarachnoid hemorrhage: a correlative microdialysis-PET study. Stroke (2004) 35(3):638-43. doi:10.1161/01. STR.0000116101.66624.F1

41. Schmidt JM, Ko SB, Helbok R, Kurtz P, Stuart RM, Presciutti M, et al. Cerebral perfusion pressure thresholds for brain tissue hypoxia and metabolic crisis after poor-grade subarachnoid hemorrhage. Stroke (2011) 42(5):1351-6. doi:10.1161/STROKEAHA.110.596874

42. Schulz MK, Wang LP, Tange M, Bjerre P. Cerebral microdialysis monitoring: determination of normal and ischemic cerebral metabolisms in patients with aneurysmal subarachnoid hemorrhage. J Neurosurg (2000) 93(5):808-14 doi:10.3171/jns.2000.93.5.0808

43. Skjoth-Rasmussen J, Schulz M, Kristensen SR, Bjerre P. Delayed neurological deficits detected by an ischemic pattern in the extracellular cerebral metabolites in patients with aneurysmal subarachnoid hemorrhage. J Neurosurg (2004) 100(1):8-15. doi:10.3171/jns.2004.100.1.0008

44. Unterberg AW, Sakowitz OW, Sarrafzadeh AS, Benndorf G, Lanksch WR. Role of bedside microdialysis in the diagnosis of cerebral vasospasm following aneurysmal subarachnoid hemorrhage. J Neurosurg (2001) 94(5):740-9. doi:10.3171/jns.2001.94.5.0740

45. Al-Rawi PG, Zygun D, Tseng MY, Hutchinson PJ, Matta BF, Kirkpatrick PJ. Cerebral blood flow augmentation in patients with severe subarachnoid haemorrhage. Acta Neurochir Suppl (2005) 95:123-7. doi:10.1007/3211-32318-X_27

46. Helbok R, Kurtz P, Schmidt JM, Stuart RM, Fernandez L, Malhotra R, et al. Effect of mannitol on brain metabolism and tissue oxygenation in severe haemorrhagic stroke. J Neurol Neurosurg Psychiatry (2011) 82(4):378-83. doi:10.1136/jnnp.2009.198754

47. Kurtz P, Schmidt JM, Claassen J, Carrera E, Fernandez L, Helbok R, et al. Anemia is associated with metabolic distress and brain tissue hypoxia after subarachnoid hemorrhage. Neurocrit Care (2010) 13(1):10-6. doi:10.1007/ s12028-010-9357-y

48. Kurtz P, Helbok R, Claassen J, Schmidt JM, Fernandez L, Stuart RM, et al. The effect of packed red blood cell transfusion on cerebral oxygenation and metabolism after subarachnoid hemorrhage. Neurocrit Care (2016) 24(1):118-21. doi:10.1007/s12028-015-0180-3

49. Nagel A, Graetz D, Vajkoczy P, Sarrafzadeh AS. Decompressive craniectomy in aneurysmal subarachnoid hemorrhage: relation to cerebral perfusion pressure and metabolism. Neurocrit Care (2009) 11(3):384-94. doi:10.1007/ s12028-009-9269-x

50. Nagel A, Graetz D, Schink T, Frieler K, Sakowitz O, Vajkoczy P, et al. Relevance of intracranial hypertension for cerebral metabolism in aneurysmal subarachnoid hemorrhage. Clinical article. J Neurosurg (2009) 111(1):94-101. doi:10.3171/2009.1.JNS08587

51. Oddo M, Frangos S, Milby A, Chen I, Maloney-Wilensky E, Murtrie EM, et al. Induced normothermia attenuates cerebral metabolic distress in patients with aneurysmal subarachnoid hemorrhage and refractory fever. Stroke (2009) 40(5):1913-6. doi:10.1161/STROKEAHA.108.534115

52. Oddo M, Milby A, Chen I, Frangos S, MacMurtrie E, Maloney-Wilensky E, et al. Hemoglobin concentration and cerebral metabolism in patients with aneurysmal subarachnoid hemorrhage. Stroke (2009) 40(4):1275-81. doi:10.1161/STROKEAHA.108.527911

53. Samuelsson C, Howells T, Kumlien E, Enblad P, Hillered L, RonneEngstrom E. Relationship between intracranial hemodynamics and microdialysis markers of energy metabolism and glutamate-glutamine turnover in patients with subarachnoid hemorrhage. Clinical article. J Neurosurg (2009) 111(5):910-5. doi:10.3171/2008.8.JNS0889

54. Schiefecker AJ, Pfausler B, Beer R, Sohm F, Sabo J, Knauseder V, et al. Parenteral diclofenac infusion significantly decreases brain-tissue oxygen tension in patients with poor-grade aneurysmal subarachnoid hemorrhage. Crit Care (2013) 17(3):R88. doi:10.1186/cc12714

55. Springborg JB, Moller C, Gideon P, Jorgensen OS, Juhler M, Olsen NV. Erythropoietin in patients with aneurysmal subarachnoid haemorrhage: a double blind randomised clinical trial. Acta Neurochir (Wien) (2007) 149(11):1089-101; discussion 1101. doi:10.1007/s00701-007-1284-Z

56. Stuart RM, Helbok R, Kurtz P, Schmidt M, Fernandez L, Lee K, et al. Highdose intra-arterial verapamil for the treatment of cerebral vasospasm after subarachnoid hemorrhage: prolonged effects on hemodynamic parameters and brain metabolism. Neurosurgery (2011) 68(2):337-45; discussion 345 . doi:10.1227/NEU.0b013e318201be47

57. Helbok R, Schmidt JM, Kurtz P, Hanafy KA, Fernandez L, Stuart RM, et al. Systemic glucose and brain energy metabolism after subarachnoid hemorrhage. Neurocrit Care (2010) 12(3):317-23. doi:10.1007/s12028-0099327-4

58. Kinoshita K, Moriya T, Utagawa A, Sakurai A, Mukoyama T, Furukawa M, et al. Change in brain glucose after enteral nutrition in subarachnoid hemorrhage. J Surg Res (2010) 162(2):221-4. doi:10.1016/j.jss.2009.06.009

59. Kofler M, Schiefecker AJ, Beer R, Gaasch M, Rhomberg P, Stover J, et al. Enteral nutrition increases interstitial brain glucose levels in 
poor-grade subarachnoid hemorrhage patients. JCereb Blood Flow Metab (2017). doi:10.1177/0271678X17700434

60. Kurtz P, Claassen J, Helbok R, Schmidt J, Fernandez L, Presciutti M, et al. Systemic glucose variability predicts cerebral metabolic distress and mortality after subarachnoid hemorrhage: a retrospective observational study. Crit Care (2014) 18(3):R89. doi:10.1186/cc13857

61. Oddo M, Schmidt JM, Carrera E, Badjatia N, Connolly ES, Presciutti M, et al. Impact of tight glycemic control on cerebral glucose metabolism after severe brain injury: a microdialysis study. Crit Care Med (2008) 36(12):3233-8. doi:10.1097/CCM.0b013e31818f4026

62. Schlenk F, Vajkoczy P, Sarrafzadeh A. Inpatient hyperglycemia following aneurysmal subarachnoid hemorrhage: relation to cerebral metabolism and outcome. Neurocrit Care (2009) 11(1):56-63. doi:10.1007/s12028-009-9222-z

63. Schlenk F, Nagel A, Graetz D, Sarrafzadeh AS. Hyperglycemia and cerebral glucose in aneurysmal subarachnoid hemorrhage. Intensive Care Med (2008) 34(7):1200-7. doi:10.1007/s00134-008-1044-5

64. Schlenk F, Graetz D, Nagel A, Schmidt M, Sarrafzadeh AS. Insulin-related decrease in cerebral glucose despite normoglycemia in aneurysmal subarachnoid hemorrhage. Crit Care (2008) 12(1):R9. doi:10.1186/cc6776

65. Schlenk F, Sarrafzadeh AS. Is continuous insulin treatment safe in aneurysmal subarachnoid hemorrhage? Vasc Health Risk Manag (2008) 4(4):885-91. doi:10.2147/VHRM.S1924

66. Schmidt JM, Claassen J, Ko SB, Lantigua H, Presciutti M, Lee K, et al. Nutritional support and brain tissue glucose metabolism in poor-grade SAH: a retrospective observational study. Crit Care (2012) 16(1):R15. doi:10.1186/ cc11160

67. Zetterling M, Hillered L, Enblad P, Karlsson T, Ronne-Engstrom E. Relation between brain interstitial and systemic glucose concentrations after subarachnoid hemorrhage. J Neurosurg (2011) 115(1):66-74. doi:10.3171/2011.3.JNS10899

68. Antunes AP, Schiefecker AJ, Beer R, Pfausler B, Sohm F, Fischer M, et al. Higher brain extracellular potassium is associated with brain metabolic distress and poor outcome after aneurysmal subarachnoid hemorrhage. Crit Care (2014) 18(3):R119. doi:10.1186/cc13916

69. Cesarini KG, Enblad P, Ronne-Engstrom E, Marklund N, Salci K, Nilsson P, et al. Early cerebral hyperglycolysis after subarachnoid haemorrhage correlates with favourable outcome. Acta Neurochir (Wien) (2002) 144(11):1121-31. doi:10.1007/s00701-002-1011-9

70. Dizdarevic K, Hamdan A, Omerhodzic I, Kominlija-Smajic E. Modified Lund concept versus cerebral perfusion pressure-targeted therapy: a randomised controlled study in patients with secondary brain ischaemia. Clin Neurol Neurosurg (2012) 114(2):142-8. doi:10.1016/j.clineuro.2011.10.005

71. Kett-White R, Hutchinson PJ, Al-Rawi PG, Gupta AK, Pickard JD, Kirkpatrick PJ. Adverse cerebral events detected after subarachnoid hemorrhage using brain oxygen and microdialysis probes. Neurosurgery (2002) 50(6):1213-21; discussion 1221-2. doi:10.1097/00006123-200206000-00008

72. Oddo M, Levine JM, Frangos S, Maloney-Wilensky E, Carrera E, Daniel RT, et al. Brain lactate metabolism in humans with subarachnoid hemorrhage. Stroke (2012) 43(5):1418-21. doi:10.1161/STROKEAHA.111.648568

73. Omerhodzic I, Dizdarevic K, Rotim K, Hajdarpasic E, Niksic M, BejticCustovic E, et al. Cerebral microdialysis: perioperative monitoring and treatment of severe neurosurgical patient. Acta Clin Croat (2011) 50(1):13-20.

74. Staub F, Graf R, Gabel P, Kochling M, Klug N, Heiss WD. Multiple interstitial substances measured by microdialysis in patients with subarachnoid hemorrhage. Neurosurgery (2000) 47(5):1106-15; discussion 1115-6. doi:10.1097/00006123-200011000-00016

75. Tholance Y, Barcelos GK, Dailler F, Renaud B, Marinesco S, Perret-Liaudet A. Biochemical neuromonitoring of poor-grade aneurysmal subarachnoid hemorrhage: comparative analysis of metabolic events detected by cerebral microdialysis and by retrograde jugular vein catheterization. Neurol Res (2015) 37(7):578-87. doi:10.1179/1743132815Y.0000000012

76. Gonzalez NR, Hamilton R, Bilgin-Freiert A, Dusick J, Vespa P, Hu X, et al. Cerebral hemodynamic and metabolic effects of remote ischemic preconditioning in patients with subarachnoid hemorrhage. Acta Neurochir Suppl (2013) 115:193-8. doi:10.1007/978-3-7091-1192-5_36

77. Noske DP, Peerdeman SM, Comans EF, Dirven CM, Knol DL, Girbes AR, et al. Cerebral microdialysis and positron emission tomography after surgery for aneurysmal subarachnoid hemorrhage in grade I patients. Surg Neurol (2005) 64(2):109-15; discussion 115. doi:10.1016/j.surneu.2004.09.036

78. Sakowitz OW, Santos E, Nagel A, Krajewski KL, Hertle DN, Vajkoczy P, et al. Clusters of spreading depolarizations are associated with disturbed cerebral metabolism in patients with aneurysmal subarachnoid hemorrhage. Stroke (2013) 44(1):220-3. doi:10.1161/STROKEAHA.112.672352

79. Sarrafzadeh A, Santos E, Wiesenthal D, Martus P, Vajkoczy P, Oehmchen M, et al. Cerebral glucose and spreading depolarization in patients with aneurysmal subarachnoid hemorrhage. Acta Neurochir Suppl (2013) 115:143-7. doi:10.1007/978-3-7091-1192-5_28

80. Schlenk F, Frieler K, Nagel A, Vajkoczy P, Sarrafzadeh AS. Cerebral microdialysis for detection of bacterial meningitis in aneurysmal subarachnoid hemorrhage patients: a cohort study. Crit Care (2009) 13(1):R2. doi:10.1186/ cc7689

81. Shuaib A, Kanthan R, Goplen G, Griebel R, el-Azzouni H, Miyashita H, et al. In-vivo microdialysis study of extracellular glutamate response to temperature variance in subarachnoid hemorrhage. Acta Neurochir Suppl (1996) 67:53-8.

82. Stocchetti N, Protti A, Lattuada M, Magnoni S, Longhi L, Ghisoni L, et al. Impact of pyrexia on neurochemistry and cerebral oxygenation after acute brain injury. J Neurol Neurosurg Psychiatry (2005) 76(8):1135-9. doi:10.1136/ jnnp.2004.041269

83. Vergouwen MD, Vermeulen M, van Gijn J, Rinkel GJ, Wijdicks EF, Muizelaar JP, et al. Definition of delayed cerebral ischemia after aneurysmal subarachnoid hemorrhage as an outcome event in clinical trials and observational studies: proposal of a multidisciplinary research group. Stroke (2010) 41(10):2391-5. doi:10.1161/STROKEAHA.110.589275

84. van den Berghe G, Wouters P, Weekers F, Verwaest C, Bruyninckx F, Schetz $\mathrm{M}$, et al. Intensive insulin therapy in critically ill patients. N Engl J Med (2001) 345(19):1359-67. doi:10.1056/NEJMoa011300

85. Investigators N-SS, Finfer S, Chittock DR, Su SY, Blair D, Foster D, et al. Intensive versus conventional glucose control in critically ill patients. $N$ Engl J Med (2009) 360(13):1283-97. doi:10.1056/NEJMoa0810625

86. Wartenberg KE, SchmidtJM, Claassen J, Temes RE, Frontera JA, OstapkovichN, et al. Impact of medical complications on outcome after subarachnoid hemorrhage. Crit Care Med (2006) 34(3):617-23; quiz 624. doi:10.1097/01. CCM.0000201903.46435.35

Conflict of Interest Statement: The authors declare that the research was conducted in the absence of any commercial or financial relationships that could be construed as a potential conflict of interest.

Copyright (־ 2017 Helbok, Kofler, Schiefecker, Gaasch, Rass, Pfausler, Beer and Schmutzhard. This is an open-access article distributed under the terms of the Creative Commons Attribution License (CC BY). The use, distribution or reproduction in other forums is permitted, provided the original author(s) or licensor are credited and that the original publication in this journal is cited, in accordance with accepted academic practice. No use, distribution or reproduction is permitted which does not comply with these terms. 